\title{
Eventos y prácticas de literacidad en torno a la formación literaria en educación básica en México
}

Literacy events and practices around literary training in basic education in Mexico

\author{
Volumen 22, Número 1 \\ Enero - Abril \\ pp. 1-36
}

\begin{abstract}
María de los Ángeles Galindo Ruiz de Chávez Jazmín Rocío Castro Magaña
\end{abstract}

\section{Citar este documento según modelo APA}

Galindo Ruiz de Chávez, María de los Ángeles., y Castro Magaña, Jazmín Rocío. (2022). Eventos y prácticas de literacidad en torno a la formación literaria en educación básica en México. Revista Actualidades Investigativas en Educación, 22(1), 1-36. Doi. https://doi.org/10.15517/aie.v22i1.47444 


\title{
Eventos y prácticas de literacidad en torno a la formación literaria en educación básica en México
}

Literacy events and practices around literary training in basic education in Mexico

\author{
María de los Ángeles Galindo Ruiz de Chávez ${ }^{1}$ \\ Jazmín Rocío Castro Magaña²
}

\begin{abstract}
Resumen: En este artículo científico se presentan resultados descriptivos sobre los eventos y prácticas de literacidad en los que participan el profesorado y alumnado en el ámbito de la literatura dentro de las asignaturas Español y Lengua Materna Español de educación básica en México. La literacidad literaria busca formar lectores que disfruten, comprendan y aprecien las obras literarias; además, reconoce que la lectura y la escritura de obras literarias se convierte en una práctica donde se socializa y se crea significado de acuerdo con los valores, creencias e identidades de la comunidad donde se experimenta. La investigación fue etnográfica realizada en una escuela primaria pública de Hermosillo, Sonora, México, durante enero y febrero de 2020, en la que participaron 12 docentes y 144 estudiantes. Los datos arrojados por el cuestionario, la entrevista focal y la observación manifiestan: a) una disociación en la política educativa y la práctica en la escuela en torno al fomento y la apreciación literaria, b) los libros de texto Español Lecturas no son utilizados porque las actividades del texto básico Español y Lengua Materna Español, no están vinculadas entre sí, c) se considera que las prácticas sociales del lenguaje son complejas para implementarse en el aula y que están descontextualizadas de los intereses del estudiantado y, d) existe una incongruencia entre las evaluaciones externas de calidad educativa con lo establecido en los planes curriculares que convergen actualmente: 2011 y 2017. En conclusión, existe un contexto tenso porque el profesorado se ve obligado a tomar decisiones entre sus prácticas didácticas, sus creencias docentes y las exigencias de la política educativa; esta tensión impide que el fomento y la enseñanza de la literatura y de la lectoescritura promuevan la construcción de significados, donde el estudiantado construya su propio discurso y donde se haga posible la interdisciplinariedad e intertextualidad.
\end{abstract}

Palabras clave: enseñanza literatura, relación estudiante-escuela, educación básica, técnica didáctica

Abstract: This article presents descriptive results on the events and literacy practices in which teachers and students participate in the field of literature within the subjects Spanish and Mother Tongue. Spanish of basic education in Mexico. Literary literacy seeks to train readers who enjoy, understand, and appreciate literary works. In addition, it recognizes that the reading and writing of literary works becomes a practice where meaning is socialized and created in accordance with the values, beliefs, and identities of the community where it is experienced. The research was ethnographic carried out in a public elementary school in Hermosillo, Sonora. Mexico, during January and February 2020, in which 12 teachers and 144 students participated. The data produced by the questionnaire, the focal interview and the observation show: a) a dissociation in the educational policy and the practice in the school around the promotion and literary appreciation, b) the Spanish Lecturas textbooks are not used because the activities of the basic Spanish text and Spanish Mother Language are not linked to each other, c) it is considered that the social practices of the language are very complex to be implemented in the classroom and that they are decontextualized from the interests of the student body and, d) there is an incongruity between the external evaluations of educational quality with what is established in the curricular plans that currently converge: 2011 and 2017. In conclusion, there is a tense context because teachers are forced to make decisions between their didactic practices, their teaching beliefs and the demands of educational policy; this tension prevents that the promotion and teaching of literature and literacy from encouraging the construction of meanings, where the student body builds their own discourse and where interdisciplinarity and intertextuality are made possible.

Keywords: literature education, school student relationship, basic education, classroom techniques ${ }^{1}$ Profesora de la Universidad de Sonora, Sonora, México. Doctora en Educación por la Educación
en la Universidad Nacional de Educación a Distancia (UNED, España). Dirección electrónica:
angeles.galindo@unison.mx Orcid https://orcid.org/0000-0003-2201-2275

2 Egresada de la Licenciatura en Literaturas Hispánicas de la Universidad de Sonora, Sonora, México. Maestría en Humanidades de la Universidad de Sonora. Dirección electrónica: a9823882@unison.mx Orcid https://orcid.org/0000-0003-0876-9511

Artículo recibido: 16 de junio, 2021

Enviado a corrección: 15 de setiembre, 2021

Aprobado: 6 de diciembre, 2021 


\section{Introducción}

En este artículo se presentan parte de los resultados de una investigación más amplia coordinada por la Maestría en Humanidades de la Universidad de Sonora, México, y auspiciada por el Consejo Nacional de Ciencia y Tecnología (CONACYT). En ella se buscó describir y comprender los eventos y prácticas de literacidad en los que participan el profesorado y alumnado en el ámbito de la literatura dentro de las asignaturas Español y Lengua Materna. Español de educación básica en México.

La literatura se enlaza a la literacidad cuando se busca formar lectoras y lectores que la disfruten, que la comprendan, la aprecien. Pero también, cuando se reconoce que la lectura y la escritura de obras literarias se convierte en una práctica donde se socializa y se crea significado de acuerdo con los valores, creencias e identidades de la comunidad donde se experiencia. Para lograrlo, es importante hacer un giro en la visión centrada en la obra literaria y en los autores, a una visión centrada en el lector. Las implicaciones de este viraje son comprender que no solo existe la obra literaria por sí misma, sino una compleja red de factores que se interrelacionan para formar lectores competentes que, además, de poder reconocer la obra literaria y disfrutarla, puedan establecer vínculos entre la inmensidad de manifestaciones literarias. Esta red de factores está conformada por los eventos de literacidad como son: los recursos utilizados para llevar la literatura a determinados públicos, las actividades realizadas a través de métodos y estrategias didácticas, así como el contexto en el que se lleva a cabo la interacción con la obra literaria. Esa red de factores involucra, además, el reconocimiento de elementos no visibles de los implicados en el proceso didáctico, como son las normas institucionales, las creencias, los saberes y las representaciones sociales de las y los docentes, del estudiantado mismo y de los padres de familia.

La literacidad de la literatura se convierte, entonces, en un tipo de literacidad disciplinar, pues como lo afirman Montes-Silva y López-Bonilla (2016) esta es un tipo de "práctica de literacidad que se da en el marco de un dominio específico y restringido; una disciplina donde la lectura y la escritura se ven como prácticas inherentes y esenciales, las cuales pueden ser reproducidas, aprendidas y enseñadas" (p. 165). En este sentido, las obras literarias, su enseñanza, su creación, su producción, su promoción y su respectiva sanción por autoridades educativas, políticas, ideológicas y mercantiles, entre otras, son consideradas prácticas de literacidad disciplinar que involucran una cultura, conocimiento y normas a seguir por quienes participan de estas prácticas. 
En México, el término literacidad fue introducido en 2019 con la reforma del Artículo 3ro. de la Constitución Política de los Estados Unidos Mexicanos, como un concepto vinculado a la educación como derecho (Diario Oficial de la Federación, 2019), sin profundizar en su concepto. Sin embargo, y de acuerdo con lo mencionado en los párrafos anteriores, la literacidad ya se había hecho patente a lo largo las políticas educativas y de los diferente planes y programas de estudio promovidos por la Secretaría de Educación Pública (SEP) a través de la enseñanza de la lengua, la lectura y la literatura, tal y como lo documentan OrozcoLópez y Pérez-Amezcua (2021). Solo como ejemplo del recuento que estos autores han hecho se puede mencionar que, a partir del año 2000, se institucionaliza el fomento a la lectura por medio de la Ley de Fomento para la Lectura y el Libro. Después en 2001 se crea el Programa Nacional para el Fortalecimiento de la Lectura y la Escritura (PNFLE), vigente hasta el Día de hoy. A partir de aquí, se han seguido diferentes estrategias nacionales para estimular el fomento a la lectura, la escritura y la apreciación literaria como lo son: los Libros del Rincón, la Estrategia $11+1$ y la Estrategia $11+5$.

Las prácticas de literacidad que se describen en esta investigación se llevan a cabo en el contexto de una escuela primaria pública en particular, por lo que este trabajo toma como referencia dos planes de estudio para la educación básica en México: El plan de estudios de 2011 (SEP, 2011), vigente para estudiantes de 3ro. a 6to. grado, y el plan Aprendizaje clave para la educación integral del 2017 (SEP, 2017), efectivo para primero y segundo grado. Aunque estos planes tienen enfoques distintos y propósitos diferenciados, ambos se estructuran en campos formativos, uno de ellos común para uno y otro, el campo de "Lenguaje y comunicación", campo en el que, además, confluyen el concepto de prácticas sociales de lenguaje como elemento de organización curricular. Dichas prácticas se convierten en componentes centrales del campo mencionado en el plan de 2017. Un dispositivo adicionado en los programas de Lengua Materna. Español como organizador curricular, dentro del plan de 2017, son los ámbitos, uno de ellos es "literatura" el cual se relaciona con las prácticas sociales del lenguaje.

La apreciación literaria en el plan de estudios para educación primaria (SEP, 2017) parte de una perspectiva humanista, donde se espera que el estudiantado vaya adquiriendo progresivamente el goce estético y la apreciación de los diferentes géneros literarios, a la vez que se perfeccionan habilidades de interpretación, reflexión y producción de textos como parte del desarrollo de las prácticas sociales del lenguaje. Para lograr tal objetivo, la labor del docente debe guiarse según una serie de principios pedagógicos, con lo cual el profesorado 
se configura como un modelo de lector en tanto que debe dominar un conjunto de prácticas de lectura y escritura, lo que le permite compartir con el alumnado lo que lee o escribe (SEP, 2017).

Por lo anterior, en este artículo se presentan resultados descriptivos sobre los eventos y prácticas de literacidad en los que participan el profesorado y alumnado en el ámbito de la literatura dentro de las asignaturas Español y Lengua Materna. Español de educación básica en México. Particularmente, se describen los eventos y prácticas relacionados con los libros de texto Español, Español Lengua Materna y Español Lecturas como artefactos idóneos para impulsar el fomento lector y apreciación literaria, la cultura escolar en la que confluye esta relación; y las creencias del profesorado en torno al ámbito literario dentro del enfoque humanista del modelo educativo actual. El trabajo presenta el marco teórico sobre los eventos y prácticas de literacidad, incluido el pensamiento del profesorado; la cultura escolar y la formación literaria; se muestra el marco metodológico para realizar la descripción de las prácticas letradas de una escuela primaria en torno a la formación literaria y, por último, se da cuenta de los eventos y prácticas de literacidad cuando se busca formar en la apreciación de la literatura y alfabetizar desde una perspectiva sociocultural.

\section{Referente teórico}

\subsection{Literacidad y sus elementos visibles e invisibles}

La literacidad es un anglicismo copiado casi literalmente de literacy, y que ha sido traducida como "alfabetización", sin embargo, tiene una concepción más amplia que solo el saber leer y escribir. La literacidad, enmarcada en los "Nuevos Estudios de Literacidad" (Barton y Hamilton, 2004; Gee 2015; Street, 2009; Zavala, 2008), concibe a la lectura y la escritura como "prácticas sociales", esto es, no deshecha la idea de enseñar a leer y escribir, sino que va más allá de la estandarización o la pluralidad, la literacidad busca comprender lo que una comunidad hace con lo que lee y lo que escribe, es decir, con sus prácticas discursivas.

La comprensión de lo que una comunidad realiza con lo que lee y lo que escribe se suscribe a la perspectiva sociocultural. Sin embargo, esto no quiere decir que no se deban considerar las perspectivas lingüística y psicolingüística como lo proponen Cassany (2008) y Kucer (2014) sino que, además, es importante entender el contexto cultural en el que se dan las prácticas discursivas de lectura y escritura en un tiempo determinado, donde el lector atribuye significado a través de un conjunto de ideas, creencias y valores, así como de principios conceptuales que cada asociación social o cultural le otorga (Gee, 2004; Street, 
2017). Kucer (2014), además, propone como cuarta dimensión, el desarrollo de la literacidad, es decir, llevar a cabo intervenciones didácticas donde las perspectivas lingüística, psicolingüística y sociocultural se pongan en juego.

Para Gee, las prácticas de literacidad en la escuela son un reflejo de las visiones y políticas de las instituciones hegemónicas con poder en nuestra sociedad, por lo que las enseñanzas de los y las docentes reproducen lo que las estructuras dominantes imponen, mismas que pueden ser distintas a la identidad, prácticas y valores del alumnado que no pertenece a esa cultura hegemónica (2004, p. 24). Sin embargo, hay voces que defienden que las prácticas sociales de lectura y escritura en el aula dependen, también, de las decisiones del profesorado. Estas decisiones se fundamentan, como lo mencionan Cambra y Palou, en redes cognitivas conformadas por "teorías implícitas, concepciones, intuiciones, creencias, imágenes y saberes prácticos de los profesores" (2007, p. 150).

Por otra parte, Barton y Hamilton (2004) explican la esencia de la literacidad desde la visión de la teoría social y lo hacen a través de seis proposiciones. Aquí se transcriben cada una de ellas.

1) La literacidad se comprende mejor como un conjunto de prácticas sociales que pueden ser inferidas a partir de eventos mediados por textos escritos. 2) Hay diferentes literacidades asociadas con diferentes ámbitos de la vida. 3) Las prácticas de literacidad están modeladas por las instituciones sociales y por las relaciones de poder, algunas se vuelven más dominantes, visibles e influyentes que otras. 4) Las prácticas de literacidad tienen un propósito y están insertas en objetivos sociales y prácticas culturales más amplias. 5) La literacidad se haya situada históricamente. 6) Las prácticas letradas cambian y las nuevas se adquieren con frecuencia, por medio de procesos informales de aprendizaje y de construcción de sentido. (p. 113)

Además de la noción de prácticas de literacidad, que es la forma cultural en la que se utiliza la literacidad según los seis principios ya descritos, existen otros dos elementos importantes que constituyen esta teoría, como lo son los acontecimientos (eventos) y prácticas de literacidad. Mientras que las prácticas de literacidad son más abstractas y no son observables puesto que "implican una serie de valores, actitudes, sentimientos y relaciones sociales" (Barton y Hamilton, 2004, p. 112), los eventos se encuentran situados en un contexto social, son regulados por las prácticas de literacidad, y por lo tanto se pueden observar en instituciones sociales como la familia, la escuela, el gobierno, etc. Para estos autores los 
dominios son situaciones contextuales con características únicas en donde la literacidad se asimila y se pone en práctica y utiliza (Barton y Hamilton, 2004, p.117), por ejemplo, la clase de matemáticas o de ciencias o lengua.

Los eventos de literacidad implican textos y estos a su vez se organizan de acuerdo con las prácticas en dominios específicos, "la literacidad se entiende mejor como un conjunto de prácticas sociales que pueden ser inferidas a partir de eventos mediados por textos escritos" (Barton y Hamilton, 2004, p. 114). Se entiende entonces que los eventos se deben a las prácticas de literacidad situadas en dominios específicos conformando con ello distintas literacidades. Para una mayor comprensión sobre las prácticas y eventos de literacidad se presentan sus aspectos diversos en la Tabla 1.

Tabla 1.

Componentes estructurales de la literacidad: eventos y prácticas de literacidad

\begin{tabular}{ll}
\hline \multicolumn{1}{c}{$\begin{array}{c}\text { Aspectos tangibles } \\
\text { eventos de literacidad }\end{array}$} & \multicolumn{1}{c}{$\begin{array}{c}\text { Aspectos no tangibles } \\
\text { prácticas de literacidad }\end{array}$} \\
\hline \hline $\begin{array}{l}\text { Integrantes: las personas que interactúan los } \\
\text { diferentes textos. }\end{array}$ & $\begin{array}{l}\text { Los participantes ocultos: otras personas o } \\
\text { grupos de personas involucradas en las relaciones } \\
\text { sociales de producir, interpretar, circular y regular } \\
\text { los textos escritos. }\end{array}$ \\
\hline $\begin{array}{l}\text { Medio ambiente: Son los escenarios donde se } \\
\text { lleva a cabo la interacción. }\end{array}$ & $\begin{array}{l}\text { El dominio de la práctica dentro del cual el evento } \\
\text { se desarrolla y adquiere sentido y propósito social. }\end{array}$ \\
\hline $\begin{array}{l}\text { Dispositivos: son los objetos materiales, } \\
\text { accesorios e instrumentos que entran interacción } \\
\text { (incluidos los textos). }\end{array}$ & $\begin{array}{l}\text { Todos los otros recursos que se integran a la } \\
\text { práctica de la literacidad, incluidos los valores, } \\
\text { entendimientos (sobreentendidos) formas de } \\
\text { pensar y sentir, habilidades y conocimientos. }\end{array}$ \\
\hline $\begin{array}{l}\text { Acciones: Tareas que llevan a cabo los partícipes } \\
\text { en el evento de literacidad. }\end{array}$ & $\begin{array}{l}\text { Itinerarios y reglas: constituidas que permiten y } \\
\text { sistematizan las tareas; las normativas de ajuste y } \\
\text { elegibilidad: quien puede o no participar en } \\
\text { actividades particulares. }\end{array}$ \\
\hline \hline
\end{tabular}

\section{Fuente: Mary Hamilton, 2000, p. 17}

Como podemos observar, para que la enseñanza de la lectura y la escritura se lleven a cabo como práctica social, en nuestro caso de la lectura literaria en la escuela primaria, se tienen que poner en juego una red de factores que se articulan de forma dinámica en la que cada factor ejerce fuerza sobre el resto, de manera rizomática, como lo mencionan Fardella y Carvajal (2018) al explicar las cualidades de las prácticas como unidad social. No obstante, pueden existir factores que ejerzan mayor fuerza sobre otros y que repercutan en la acción educativa, como lo son las creencias docentes.

Cambra y Palou (2007) estructuran las creencias del profesorado en tres niveles: las enmarcadas en el ámbito personal, las que corresponden a lo socialmente compartido entre 
colegas y a los elementos habitualmente aceptados durante el proceso de enseñanzaaprendizaje. Estos niveles conforman el modelo CRS -creencias, representaciones y saberes. Estos sistemas cognitivos cuando interrelacionan van a repercutir en las decisiones que el profesorado toma en el aula, pues las y los docentes hacen uso de aquellas opciones que tiene a su disposición dentro de su práctica profesional, como pueden ser: su experiencia lectora, los aspectos teóricos, las reformas curriculares vigentes, diversas estrategias didácticas, su formación docente, la cultura de la escuela, las innovaciones tecnológicas, los libros de texto y su propia experiencia docente, entre otros.

Diversos trabajos dan cuenta de la relación de las creencias del profesorado con las prácticas docentes, la formación del profesorado, el perfil lector de las y los docentes, el profesorado como modelo lector y la educación literaria. En el primer caso se enfatiza que la reflexión sobre la práctica y sobre el pensamiento docente permite desarrollar un proceso metacognitivo que incide en las creencias y en las representaciones de las y los docentes con el objetivo claro de la innovación y transformación de la práctica (Cambra y Palou, 2007). En cuanto al sistema CRS en la formación literaria, Munita (2013 y 2018) destaca que la manera de valorar la literatura y su inserción en el aula depende del conocimiento que el profesorado tenga del sistema literario, de la concepción que tenga sobre de la lectura y su capacidad para valorarla teniendo en cuenta la multiplicidad de aspectos formativos y estéticos; además, de la propia formulación de identidad docente-lectora, de las perspectivas de acción y el reconocimiento de la lectura como práctica social, así como, la propia experiencia lectora del docente-mediador en la relación didáctica.

Si en algo coinciden Lamas (2017), Munita (2018), y Muñoz et al. (2020) es en que las creencias del profesorado pueden ser transformadas y por lo tanto sus prácticas letradas en el aula a través de acciones en la formación inicial docente. Dentro de sus propuestas están la de incorporar la modalidad de club de lectura o círculos literarios con el objetivo de transformar la autoimagen lectora y la resignificación del goce estético, así como el potenciar el acceso a una diversidad de procesos de lectura sobre literatura infantil y juvenil.

\subsection{Cultura escolar}

La palabra cultura proviene del latín cultus, ūs, que a su vez se deriva de la voz colō (Segura-Munguía, 2003, p. 182) que significa cultivar o cuidar; primero se relacionó con la acción humana, por ejemplo, con la acción de cultivar la tierra y después adquirió una connotación metafórica, como el cultivo del alma o del espíritu, relacionándose con el 
desarrollo de la persona (Pérez-Gómez, 2004). Hoy, cuando se dice que alguien "tiene cultura", se quiere decir que es culto, cultivado, instruido, educado, incluso, se relaciona con las artes en general. Según Franz Boas (1930, cit. en Kahn, 1975, p. 14)

La cultura incluye todas las manifestaciones de los hábitos sociales de una comunidad, las reacciones del individuo en la medida en que se ven afectadas por las costumbres del grupo en el que vive, y los productos de las actividades humanas en la medida en que se ven determinadas por dichas costumbres.

Para Geertz la cultura es "esa urdimbre y el análisis de la cultura ha de ser, por lo tanto, no una ciencia experimental en busca de leyes, sino una ciencia interpretativa en busca de significaciones" (2003, p. 20). Estas dos últimas definiciones hacen referencia a los hábitos que el individuo adquiere, conserva y transmite, y que constituyen una determinada "forma de ser" ante la vida en beneficio o perjuicio de este, por lo que, según el último autor, la cultura debe ser interpretada.

En el ámbito escolar la cultura, como la de cualquier grupo, es un concepto complejo debido a su naturaleza cambiante (Elías, 2015) en tanto que tiene características de preservación de significados y al mismo tiempo en constante transformación. Para este estudio nos apoyamos en el concepto de Pérez (2004), quien define la cultura escolar como:

Entiendo por tal el conjunto de significados y comportamientos que genera la escuela como institución social. Las tradiciones, costumbres, rutinas, rituales e inercias que la escuela estimula y se esfuerza en conservar y reproducir, condicionan claramente el tipo de vida que en ella se desarrolla y se refuerzan la vigencia de valores, creencias y expectativas ligadas a la vida social de los grupos que constituyen la institución escolar. (p. 127)

Tales significados y comportamientos son resultado de la cultura de quienes forman parte de la escuela, por lo que éstos pueden facilitar u obstaculizar el desarrollo lector y de apreciación literaria del estudiantado.

Algunas investigaciones como la de Julio-Maturana, Conejeros-Solar, Rojas-Aravena, , Mohammad-Jiménez, Castillo y Cortés-León (2016) evidencian que las creencias del profesorado sobre la cultura familiar y popular de la que provienen las y los estudiantes inciden en su aprendizaje y desarrollo integral. Otros trabajos (como los que abajo se señalan) muestran que muchos de los aspectos de la cultura escolar como las ceremonias escolares 
además de ser un vínculo entre la comunidad y la escuela son también un proceso impositivo para crear identidad y significaciones para normar una conciencia ciudadana a través de las prácticas de los actores de la institución educativa, quienes reproducen, a través de los rituales, una ideología dominante (Escolano, 2020; Galindo-Aguilar, 2009; Gutiérrez-Álvarez y Rafael-Ballesteros, 2020; Trujillo, 2010; Vain 2019).

\subsection{Formación literaria}

Vincular la literacidad con la formación literaria implica llevar a cabo un reconocimiento, como lo hacen Bataller- Català y Reyes-Torres (2019), de las portaciones realizadas por varios investigadores de enseñanza de la literatura (Colomer, 1998; Díaz-Plaja, 2002; MendozaFillola, 1998) para dar un giro desde los planteamientos centrados en el autor y en la obra literaria a los planteamientos focalizados en el lector, específicamente en metodologías, recursos, teorías y creencias didácticas por los que el estudiantado ha de pasar. Se resalta de manera particular el auge de las contribuciones, las teorías del hipertexto e intertextualidad, así como de la psicología cognitiva y de la estética (Mendoza-Fillola, 2001 y Mendoza-Fillola, 2004).

Al ser la lengua el soporte de todas las materias del currículo escolar, su enseñanza se vincula con la literatura debido a su función estética, y es aprovechada como medio para desarrollar habilidades comunicativas. En este sentido, Colomer (2001) señala que la formación literaria implica maneras de fomentar la literatura desde la misma enseñanza de la lengua. Algunas de esas habilidades son la comprensión de un texto, el aprendizaje de léxico y el desarrollo fonológico, habilidades que se fomentan a través de la lectura en voz alta (Riffo et al., 2018), estrategia que contribuye a la comprensión a nivel literal e inferencial (Lastre et al., 2018).

En adición a lo anterior, formar en la experiencia literaria no solo permite el goce estético de la obra, sino que construye al sujeto dotándolo de habilidades que podrían defenderlo ante un mundo repleto de signos confusos y discursos envolventes. Cada vez es más complicado que niñas, niños y adolescentes en la medida que van desarrollando una habilidad comunicativa en interacción con los discursos dominantes, adquieran un discurso propio, pues solo se limitan a reproducir enunciados ajenos que tienen que ver con los discursos del mercado. Al respecto, Sánchez-Corral (2003) menciona que: 
Esta finalidad liberadora y educativa del lenguaje ( $y$, por lo tanto, de su enseñanza y aprendizaje) se consigue, mejor que con ningún otro discurso, mediante la práctica significante del discurso literario, puesto que en él residen aquellas virtualidades expresivas que hacen del proceso de semiosis un acto liberador frente a las restricciones propias de los (macro) enunciados del mercado. (p. 297)

Así y en concordancia con Condemarín (2003) y Bataller- Català y Reyes-Torres (2019), durante la experiencia estética, el lector no busca recuperar información, sino que se adentra en la comprensión de otras formas de ver, sentir y experimentar el mundo. Esto implica ir más allá de la reproducción de contenidos canónicos, implica también, una sensibilización sobre el contexto socio-cultural en el que los aprendices se desenvuelven y la selección de obras y estrategias didácticas acordes a las circunstancias. Al respecto y para el caso de México, afirman Aceves-Azuara y Mejía-Arauz (2015), que es poco frecuente encontrar que el profesorado realice una mediación que permita la construcción de estructuras conformadas por las interpretaciones personales y emocionales, pues su enfoque es el desarrollo de habilidades cognitivas y lingüísticas.

Por su parte, Carolina Cuesta (2019) reflexiona, para el caso argentino, pero no por ello alejado del resto de Latinoamérica, sobre los conflictos en torno a los saberes pedagógico/didácticos y a la de los docentes en relación con la enseñanza de la lengua y la literatura. Los saberes, como lo mencionamos en párrafos anteriores, forman parte de las creencias del profesorado dentro del sistema CRS propuesto por Cambra y Palou (2007). Estos conflictos, dice Cuesta, se presentan en varios aspectos como: a) la fragmentación conceptual de lengua y la literatura impuesta por el currículo oficial, b) la enseñanza de la lengua, la gramática escolar y diversidad lingüística, c) la dirección que establece el currículo sobre la enseñanza de la literatura y la lectoescritura hacia la transformación del aula en una situación/experiencia de aprendizaje y la "construcción/formación" de "lectores/subjetividades" y d) el uso de los libros de texto como orientadores de las metodologías de enseñanza.

La enseñanza de la lectoescritura y del fomento y apreciación literaria son actividades complejas en las que intervienen la cultura, la familia, las creencias y saberes de los docentes, las instituciones educativas, los modelos curriculares y otros elementos mediadores que hemos querido enmarcar en esta investigación como eventos y prácticas de literacidad. 


\section{Metodología}

\subsection{Enfoque}

Se presenta aquí una investigación cualitativa de tipo etnográfico donde se describe y analiza lo que las personas del contexto escolar hacen usualmente; en el caso de esta investigación, el objetivo es describir cómo son los eventos y prácticas de literacidad en torno al fomento de la apreciación literaria en una escuela primaria. La investigación inició en agosto del 2018 y el trabajo de campo se realizó durante los meses de enero y febrero de 2020 en una escuela primaria pública de Hermosillo Sonora, México. La inmersión en el campo pudo llevarse a cabo pues fue justo antes de que se declarara la pandemia por Covid 19, sin embargo, ya durante el período de investigación hubo ausentismo en el estudiantado por influenza.

La etnografía, dentro del enfoque cualitativo, en el caso de la educación busca una "descripción detallada de las áreas de la vida social de la escuela" (Woods, 1987, p. 24), por lo que, mencionan Lara-Guijarro y Ballesteros-Velazquez citando a Goetz y LeCompte (1988), se "pretende representar, explicar e interpretar los fenómenos educativos, las actividades y creencias de los participantes en ellos, determinar las diversas perspectivas y actividades del profesorado y alumnado, con el propósito de explicar patrones de comportamiento" (2008, p.174).

\subsection{Unidades de análisis}

Las unidades de análisis de esta investigación están conformadas por los miembros de la comunidad de la escuela primaria pública de Hermosillo, Sonora, México, específicamente, profesorado y estudiantado. El profesorado porque está implicado directamente en los eventos y prácticas de literacidad en torno a la enseñanza de la literatura. Se trabajó con 12 docentes de primero a sexto grado (8 profesoras y 4 profesores) de entre 25 y 44 años, los cuales conforman el total de docentes del plantel. El estudiantado porque ellos son los principales depositarios de las practicas ejercidas por los docentes, este grupo está conformado por 144 estudiantes de entre 6 y 12 años, de los cuales 96 son niñas, y 48 son niños. El alumnado participante se estructura de la siguiente manera: 18 estudiantes son de primer grado, 27 de segundo, 19 de tercero, 28 de cuarto, 25 de quinto y 27 de sexto. Los dos grupos por grado corresponden al turno matutino, y el número de participantes fueron quienes asistieron los Días de la visita al plantel. El trabajo de campo se llevó a cabo en un total de 20 sesiones. Doce fueron dedicadas para llevar a cabo la observación de clase de del campo Lenguaje y 
comunicación, seis sesiones más para la aplicación de cuestionarios tanto a docentes como a estudiantes, así como dos sesiones de una hora para el grupo focal. El horario fue de lunes a viernes de 8:00 a 12:00 de la mañana en las fechas comprendidas entre el 20 de enero y el 7 de febrero 2020. El Día 31 de enero se nos permitió llevar a cabo el grupo focal dentro del Consejo Técnico 3 .

La selección de las personas participantes fue de manera no probabilística, específicamente, es una muestra es de casos-tipo. Este tipo de muestreo se utiliza tanto en estudios cuantitativos como cualitativos donde el objetivo es: "la riqueza, profundidad y calidad de la información y no necesariamente la cantidad y estandarización" (Hernández et al., 2014, p. 387). Además, se consideran como elementos de análisis seis libros de texto de Español, Español. Lengua Materna y seis libros de texto de Español Lecturas.

La recopilación de la información se hizo con el consentimiento informado de las y los participantes y con la advertencia del uso confidencial de los datos. Como en esta investigación participan menores de edad, fue necesario, además, contar con la autorización de las y los padres de familia, así como con la autorización de la dirección del plantel.

\subsection{Técnicas e instrumentos}

Para recoger la información se utilizaron tres técnicas: el cuestionario, la observación participante y el grupo focal. Los eventos y prácticas de literacidad implican una serie de elementos que pueden ser tanto observables como no observables, por lo que se crearon instrumentos que pudieran dar cuenta de ambos elementos tanto en el profesorado como en el alumnado. En este sentido los instrumentos fueron:

\subsubsection{Cuestionario}

Los cuestionarios, previamente validados por expertos, se estructuran con preguntas tipo Likert con cinco alternativas posibles de respuesta en las que el profesorado y el estudiantado, podrán seleccionar una, por pregunta, o declaración. El cuestionario para las y los estudiantes consta de 23 ítems (ver Anexo 1); el del profesorado de 27 ítems (ver Anexo 2). Las preguntas se estructuraron a partir de las variables de estudio imbricadas en los eventos y prácticas de literacidad, a saber: cultura escolar (Pérez-Gómez, 2004), literacidad (Barton y Hamilton, 2004) y formación literaria (Sánchez-Corral, 2003), además del plan

\footnotetext{
${ }^{3}$ Es el órgano colegiado de mayor decisión técnico-pedagógica de cada escuela de Educación Básica, encargado de tomar y ejecutar decisiones enfocadas a alcanzar el máximo logro de los aprendizajes del alumnado de esta.
} 
curricular para educación primaria (SEP, 2017) los libros de texto de Español, Lengua Materna. Español y Español Lecturas (2019).

\subsubsection{Observación participante}

Concordamos con Baena-Paz (2017) en que "la observación participante es un procedimiento particularmente adecuado para el examen de diversas formas de conducta, donde reviste especial dificultad establecer una buena relación con los sujetos” (p.71). Para llevar a cabo la observación participante se utilizó como herramienta de observación la ficha anecdótica, misma que puede apreciarse en la Tabla 2.

\section{Tabla 2}

Ficha anecdótica para observación de las prácticas letradas en la clase de Español y Lengua Materna. Español de una escuela primaria pública. Hermosillo, Sonora, México. 2020

\section{Ficha anecdótica No.}

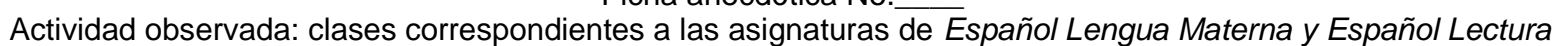

Fecha y hora:

Grupo y grado escolar:

$$
\text { Temas }
$$

Notas de lo observado

Juegos didácticos

Lecturas: docentes a estudiantes; estudiantes (voz

alta, en silencio, en grupo)

Intercambio de ideas sobre las lecturas

Material audiovisual

Recomendación de lecturas

Promoción de visitas a la biblioteca escolar

Otros

Fuente: Elaboración propia, 2020

La observación se programó para las sesiones de clases de la asignatura de Español, Lengua Materna. Español y Español Lecturas; sin embargo, en cuanto a la clase relacionada con el libro de Español Lecturas, las y los docentes no aclararon los momentos en que llevaban a cabo esta actividad, por lo que finalmente sólo se observó la clase correspondiente a la asignatura de Lengua Materna. Español, correspondiente a primero y segundo grado, y Español, asignatura correspondiente de tercero a sexto grado, pues como se mencionó al inicio de este artículo, en la escuela primaria en México, confluyen dos planes de estudio: el del 2011 y el del 2017.

Los momentos de la observación se dieron desde la programación de visitas a la escuela, es decir, se tomaron en cuenta todos los aspectos que pudieran dar pistas sobre el comportamiento de los docentes ante la literatura. Tales aspectos observados van desde la infraestructura de la escuela y equipamiento de las aulas, hasta la misma conducta de los docentes ante el trabajo de campo realizado. 


\subsubsection{Entrevista focalizada}

Otra técnica de la investigación cualitativa para recabar datos es el grupo focal. Según Martínez (1999), "el grupo focal es un método de investigación colectivista, más que individualista, y se centra en la pluralidad y variedad de las actitudes, experiencias y creencias de los participantes, y lo hace en un espacio de tiempo relativamente corto" (cit. en Hamui y Varela, 2013, p. 56).

Para este estudio, las preguntas orientadoras para llevar a cabo el encuentro intentan provocar en el profesorado auto explicaciones en torno a temas que tienen que ver con sus experiencias didácticas, así como opiniones sobre el plan curricular y en específico sobre el uso de los libros de Español, Lengua Materna. Español y Español Lecturas. Algunas de las preguntas planteadas al profesorado fueron las siguientes:

1. ¿Qué opinión tiene sobre el plan curricular?

2. ¿Aprovecha los festejos como el Día de las madres, Día de las niñas y los niños o Día de muertos para fomentar la literatura? ¿Realiza juegos didácticos durante estas celebraciones?

3. ¿Qué opinión tiene sobre los libros de texto Español, Lengua Materna. ¿Español y Español Lecturas, son apropiadas las instrucciones en ellos?

4. ¿Es suficiente el tiempo que le otorga a la asignatura Español Lengua Materna y Español Lectura para cumplir con los objetivos del plan curricular?

5. ¿Qué les parecen las prácticas sociales de lenguaje vinculadas a la literatura?

6. ¿Considera que la literatura se debería tratar como arte y coadyuvante para mejorar la comprensión lectora o sólo como herramienta para alfabetizar?

7. ¿Qué opinión tiene acerca de si la educación primaria es la base para iniciar el proceso de crear individuos productivos o la base para para seguir un proceso enfocado al desarrollo humano?

8. ¿Qué piensa sobre la idea de que el arte en las escuelas podría hacer al alumnado incompetente ante el mercado de trabajo?

\subsection{Procedimiento de análisis}

Para llevar a cabo el procedimiento de análisis, al igual que para establecer las preguntas del cuestionario, de la entrevista focal y la observación participantes se tomó como guía las variables de estudio imbricadas en los eventos y prácticas de literacidad, a saber: cultura escolar (Pérez-Gómez, 2004), literacidad (Barton y Hamilton, 2004) y formación literaria 
(Sánchez-Corral, 2003), además del plan curricular para educación primaria (SEP, 2017) los libros de texto de Español Lengua Materna, Español Lecturas, y Artística (2019).

El proceso de análisis puso en juego distintas metodologías de acuerdo con los instrumentos utilizados para que con ello se pudiera llevar a cabo una triangulación de resultados. Pues, en concordancia con Denzin "la triangulación es la combinación de metodologías en el estudio del mismo fenómeno. Sirve para clarificar el significado identificando diferentes maneras a través de las cuales es percibido el fenómeno" (1978, p.291).

En este sentido, el primer elemento de análisis fue el cuestionario aplicado a docentes y estudiantes. El análisis de las respuestas descriptivas del cuestionario tipo Likert se utilizó el programa estadístico SPSS (Statistical Package for the Social Sciences, versión 20). El cuestionario para las y los estudiantes consta de 23 ítems, las respuestas a las afirmaciones se establecieron en las siguientes categorías: 1=Nunca; 2=La mayoría de las veces no; 3=Algunas veces sí, algunas veces no; 4= La mayoría de las veces sí; 5=Siempre. El análisis de consistencia interna de este cuestionario arrojó un nivel de fiabilidad .931. El cuestionario del profesorado consta de 27 ítems con la siguiente escala de medición: 1 = Totalmente en desacuerdo, 2=Parcialmente en desacuerdo, $3=\mathrm{Ni}$ en desacuerdo ni de acuerdo, 4=Parcialmente de acuerdo y $5=$ Totalmente de acuerdo. Para presentar los porcentajes de las categorías se llevó a cabo una agrupación de los resultados, los cuales hacen referencia a la sumatoria de la escala correspondiente a: la mayoría de las veces sí y siempre, en el caso del estudiantado. En lo que se refiere a las respuestas de las y los docentes, se presenta la sumatoria de la escala: parcialmente de acuerdo y totalmente de acuerdo.

La consistencia interna del cuestionario de docentes obtuvo un Alfa de Cronbach de .876. En ambos casos, la fiabilidad nos da la certeza de que el instrumento mide lo que se prende medir.

Para el segundo instrumento, la observación participante, se estableció como un primer acercamiento de sistematización las siguientes subcategorías categorías: juegos didácticos, procesos de lectura en el aula, intercambio de ideas, disfrute de obras literarias, material audiovisual, recomendación de lecturas, entre otros, que luego fueron asignadas a las categorías prefijadas ya mencionadas en el primer párrafo de este apartado.

Para el tercer instrumento, la entrevista focal, se realizaron dos sesiones de una hora cada una, se realizaron grabaciones y luego se llevó a cabo la transcripción de las respuestas de las y los docentes. En una primera exploración del contenido, se utilizó como unidad de 
análisis frases y temas, es decir: "los núcleos de significado que componen la comunicación y aportan información para nuestro objeto de estudio" (Lara-Guijarro y Ballesteros-Velazquez, 2008, p. 389). Como regla de enumeración se utilizó la frecuencia y la dirección de las respuestas, y para el establecimiento de subcategorías, el análisis consistió en la asignación de las unidades de análisis a las categorías prefijadas: cultura escolar, literacidad y formación literaria, como se muestra en la Tabla 3.

Tabla 3.

Primera sistematización y categorización partir de la entrevista focal y la observación participante dentro de categorías teóricas, Hermosillo, Sonora. México. 2020

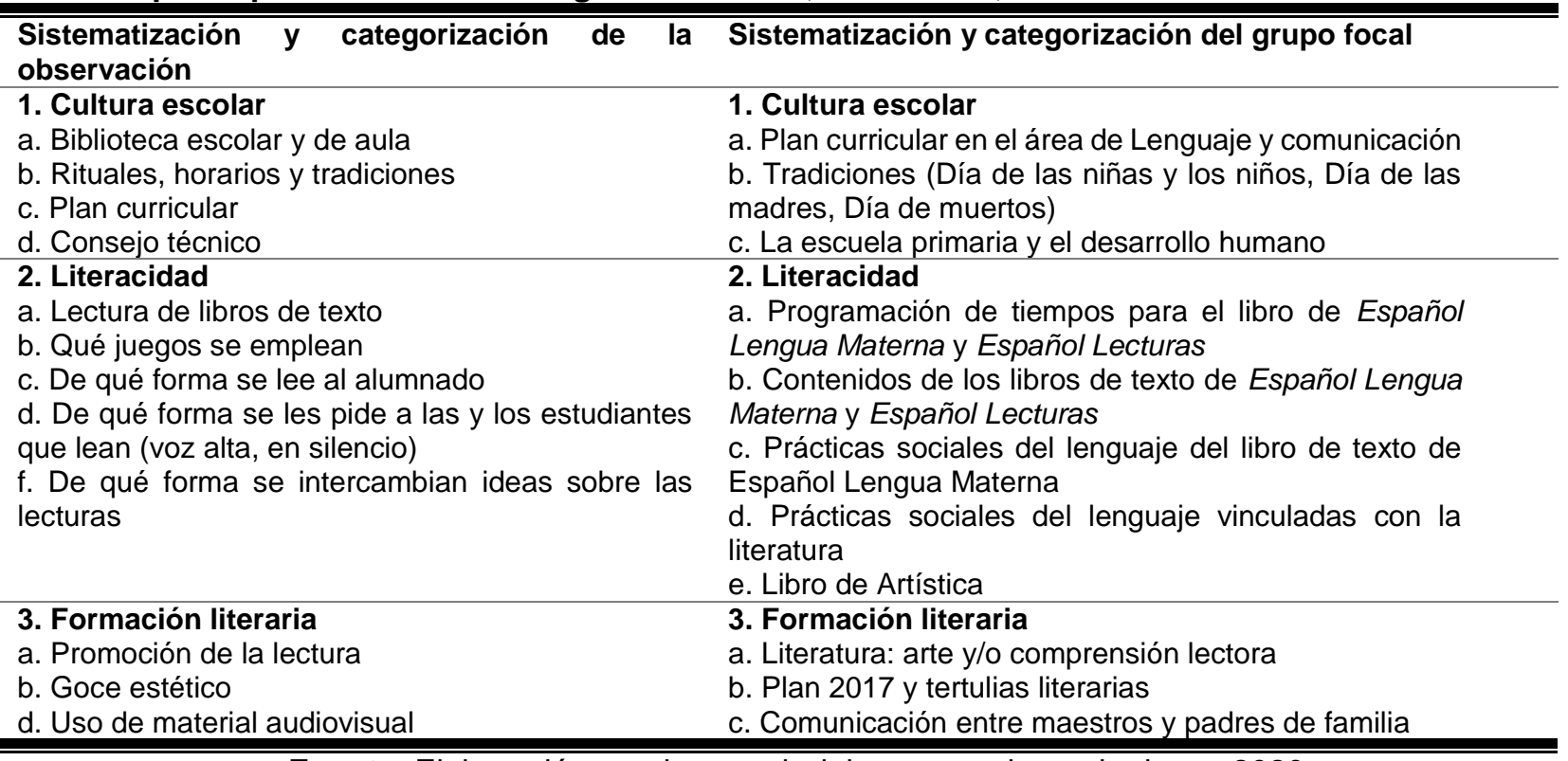

Fuente: Elaboración propia a partir del procesamiento de datos, 2020

Una vez ubicadas las subcategorías resultantes de la observación y el grupo focal dentro de las variables preestablecidas de manera teórica, se llevó a cabo otro proceso de categorización, pero ahora dentro de la propuesta de Hamilton (2000, p.17), como eventos y prácticas de literacidad. Es decir, fue necesario identificar cuáles subcategorías dentro de la cultura escolar (CE), literacidad (L) y formación literaria ( $F L)$ formaban parte de los elementos tanto visibles como no visibles de la literacidad presentes en la escuela primaria pública de Hermosillo, Sonora, México. A manera de ejemplo, este proceso se puede ver en la Tabla 4. 
Tabla 4.

Segunda sistematización y categorización partir de la entrevista focal y la observación participante dentro de las categorías de eventos y prácticas letradas, Hermosillo, Sonora. México. 2020

\begin{tabular}{|c|c|c|}
\hline & Categorías & SUBCATEGORÍAS \\
\hline \multirow{4}{*}{$\begin{array}{l}\text { EVENTOS } \\
\text { Elementos } \\
\text { visibles }\end{array}$} & Participantes & $\begin{array}{l}\text { Docentes (CE) } \\
\text { Estudiantes (CE) } \\
\text { Padres y madres de familia (CE) }\end{array}$ \\
\hline & Ambiente/Contexto & $\begin{array}{l}\text { Infraestructura de la escuela (CE) } \\
\text { Biblioteca de la escuela (CE) }\end{array}$ \\
\hline & Artefactos & $\begin{array}{l}\text { Biblioteca de aula (CE) } \\
\text { Libros de texto de Español Lengua Materna, Español Lecturas } \\
\text { (L) } \\
\text { Material audiovisual (FL) }\end{array}$ \\
\hline & Actividades & $\begin{array}{l}\text { Plan de lectura escolar (CE) } \\
\text { Recomendación de lecturas en los lunes cívicos (CE) } \\
\text { Reportes de lectura semanal (L) } \\
\text { - Intercambio de ideas sobre lecturas y juegos (L) } \\
\text { y los niños, Día de muertos, Día de la madre, Día de las niñas } \\
\text { - } 14 \text { debrero }\end{array}$ \\
\hline \multirow{4}{*}{$\begin{array}{l}\text { PRÁCTICAS } \\
\text { Elementos no } \\
\quad \text { visibles }\end{array}$} & $\begin{array}{l}\text { Participantes } \\
\text { ocultos }\end{array}$ & $\begin{array}{l}\text { * Secretaría de Educación Pública (SEP) } \\
\text { Modelos educativos vigentes (CE) } \\
\text { Plan de estudios para educación básica (CE) } \\
\text { * Con curricular (CE) } \\
\text { Consejo técnico (CE) }\end{array}$ \\
\hline & $\begin{array}{l}\text { Domino de la } \\
\text { práctica }\end{array}$ & $\begin{array}{l}\text { * Horas de clases de Español Lengua Materna y Español } \\
\text { Lecturas (CE) } \\
\text { * Literatura contenida en los libros de texto (L) }\end{array}$ \\
\hline & Otros recursos & $\begin{array}{l}\text { * Promoción de la lectura (FL) } \\
\text { - Greencias del profesorado en torno a la enseñanza de la } \\
\text { literatura (L) }\end{array}$ \\
\hline & $\begin{array}{l}\text { Rutinas } \\
\text { trayectorias }\end{array}$ & $\begin{array}{l}\text { Horarios y organización de clases (CE) } \\
\text { Conducta de las y los docentes durante las horas de clase } \\
\text { (CE) } \\
\text { Normas de comportamiento en clase (CE) }\end{array}$ \\
\hline
\end{tabular}

Fuente: Elaboración propia a partir del procesamiento de datos, 2020

En el apartado de resultados se describen, por cuestiones de espacio, solo algunas de las prácticas letradas en torno a formación literaria, específicamente, las relacionadas con los libros de textos, la cultura escolar a través de las tradiciones, las creencias sobre el desarrollo humano y la formación básica, las actividades didácticas para la lectura y literatura, así como las creencias acerca de la relación literatura como arte o como herramienta de comprensión lectora. 


\section{Resultados. Eventos y prácticas de literacidad en torno a la formación literaria en la escuela primaria}

\subsection{Libros de texto de Español Lengua Materna y Español Lecturas}

El artefacto central en el análisis de los eventos de literacidad fueron los libros de texto de Español, Lengua Materna. Español y Español Lecturas (SEP, 2019), los cuales son una herramienta importante para promover la literatura. El libro de Español Lecturas contiene una gran variedad de obras literarias de reconocidos autores nacionales y extranjeros; en cuanto a los libros de Español y Lengua Materna. Español, son un artefacto idóneo para abordar la educación literaria, tanto por el contenido de obras literarias como por las prácticas sociales del lenguaje vinculadas con la literatura. En la Tabla 5, se exponen las prácticas sociales del lenguaje contenidas en los libros de texto.

Como se puede apreciar en dicha Tabla, existe una gran variedad de actividades de lectoescritura que permiten el fomento y la apreciación de la literatura y que, en teoría, establecen la estructura para llevar a cabo intervenciones didácticas orientadas tanto al goce estético como al intercambio de ideas y análisis reflexivo acorde a la edad de niños y niñas. Por esta razón, los libros de texto son el eje del análisis de los eventos y prácticas de literacidad en torno al fomento y apreciación de la literatura en las que se incluyen las creencias del profesorado, las percepciones del alumnado, las tensiones entre la política educativa y las prácticas didácticas, entre otras. 
Tabla 5.

Prácticas sociales del lenguaje contenidas en los libros de texto de Español y Lengua Materna. Español, de primero a sexto grado de primaria, Hermosillo, Sonora. México. 2019

\begin{tabular}{|c|c|c|c|}
\hline Grado & $\begin{array}{l}\text { Plan de } \\
\text { estudios }\end{array}$ & $\begin{array}{c}\text { Libro de } \\
\text { texto }\end{array}$ & Prácticas sociales del lenguaje \\
\hline $1^{\circ}$ & 2017 & $\begin{array}{l}\text { Lengua } \\
\text { Materna. } \\
\text { Español }\end{array}$ & $\begin{array}{l}\text { Proyectos por etapas como representación de obras teatrales; Tiempo de } \\
\text { leer; donde se realizan lecturas del libro de Lectura; Pasaporte de lecturas; } \\
\text { Vamos a la biblioteca; Calaveritas literarias; Recomendamos un cuento; } \\
\text { Cuentacuentos (dictado al docente o grabación de cuento) }\end{array}$ \\
\hline $2^{\circ}$ & 2017 & $\begin{array}{l}\text { Lengua } \\
\text { Materna. }\end{array}$ & $\begin{array}{l}\text { Proyecto por etapas como escribir recomendaciones de libros; Tiempo de } \\
\text { leer (uso del libro de Lectura y preparación de lecturas en voz alta); Una } \\
\text { invitación a la lectura; Escribimos y compartimos cuentos (escritura de } \\
\text { cuentos por etapas para su posterior publicación ante la comunidad } \\
\text { escolar); Todos al teatro (lectura y análisis de obras de teatro y su posterior } \\
\text { representación); Mis lecturas favoritas. }\end{array}$ \\
\hline $3^{\circ}$ & 2011 & Español & $\begin{array}{l}\text { Elaboración de un reglamento para el servicio de la biblioteca del salón; } \\
\text { Contar y escribir chistes para publicarlos; Compartir poemas para expresar } \\
\text { sentimientos; Escribir un relato autobiográfico para compartir; Describir } \\
\text { escenarios y personajes de cuentos para elaborar un juego; Compartir } \\
\text { adivinanzas. }\end{array}$ \\
\hline $4^{\circ}$ & 2011 & Español & $\begin{array}{l}\text { Escribir trabalenguas y juegos de palabras para su publicación; Escribir } \\
\text { narraciones a partir de refranes; leer poemas en voz alta; Escribir un relato } \\
\text { a partir de narraciones mexicanas; Escribir datos biográficos de un autor de } \\
\text { la literatura infantil o juvenil. }\end{array}$ \\
\hline $5^{\circ}$ & 2011 & Español & $\begin{array}{l}\text { Reescribir relatos históricos para publicarlos; Analizar fábulas y refranes; } \\
\text { Elaborar un compendio de leyendas; Leer poemas; Escribir una obra de } \\
\text { teatro con personajes de textos narrativos; Elaborar retratos escritos de } \\
\text { personajes célebres para publicarlos. }\end{array}$ \\
\hline $6^{\circ}$ & 2011 & Español & $\begin{array}{l}\text { Escribir biografías y autobiografías para compartir; Escribir cuentos de } \\
\text { misterio o de terror para su publicación; Adaptar un cuento como obra de } \\
\text { teatro; Escribir poemas para compartir. }\end{array}$ \\
\hline
\end{tabular}

Fuente: Elaboración propia a partir de los libros de texto de Español y Lengua Materna. Español de primero a sexto grado (SEP, 2019).

En cuanto al rol que juegan los libros de texto en las prácticas docentes, por lo que se pudo observar y de acuerdo con las declaraciones de las y los docentes, el libro de Español Lecturas es un recurso opcional. Esto es, el profesorado que imparte clases en primer y segundo grado (del plan 2017) sí utiliza el libro de Español Lecturas con el objetivo de alfabetizar, mientras que las y los docentes de los otros grados (del plan 2011) no hacen uso de él. Sin embargo, hay voces entre el profesorado de 1 ro y 2 do que menciona que el libro de Español Lecturas no está vinculado al libro de Lengua Materna. Español, ni a las dinámicas de trabajo por proyecto ya que se le da más importancia a la biblioteca de aula.

"Si no lo tomas, no pasa nada y pasa todo el currículo y ahí se queda, en cambio en el plan 93 sí hacías uso de él". (D11, M, 6to)

"Venía hasta en el libro de texto del alumno, y en el recortable también estaba enfocado, yo me acuerdo mucho de cada lección que empezaba en el '93, decía "lee el texto fulanito" y nos íbamos al libro de lecturas, y toda la semana si se trataba esa lección, 
estamos usando el libro de lecturas a la par, pero ahora no siento que sea así" (D12, F, 3ro.).

De hecho, son más los libros que usamos de la biblioteca de aula que se acomodan al proyecto que estemos viendo, que, utilizando el libro de lecturas, como si el libro de lecturas fuera un libro más, equis, que se puede poner en la biblioteca de aula" (D7, F, 4to).

"El libro de Español Lectura no tiene nada que ver con el de Español Lengua Materna, no viene ninguna actividad vinculada" (D4, F, 1ro).

“No es complemento del libro de Español Lengua Materna" (D9, F, $6^{\circ}$ ).

Sin embargo, aunque el plan curricular no los obliga a usar ese recurso por no tratarse de una asignatura, los libros de texto de Español Lecturas contienen un mensaje dirigido a las y los docentes de tercero a sexto grado (plan 2011) donde se especifica que el libro tiene como propósito impulsar el desarrollo lector de las y los estudiantes a través del disfrute de la lectura como actividad lúdica; además se especifica que en el contenido de estos libros predominan los textos literarios para poner en juego diferentes habilidades de comprensión lectora como la inferencia y la interpretación, por lo que se espera que el libro Español Lecturas sea un apoyo en las actividades docentes (SEP, 2019).

En relación con las prácticas sociales del lenguaje vinculadas con la literatura y con el libro de Lengua Materna. Español, las y los docente declararon que son complejas y difíciles de aplicar al contexto real de las niñas y los niños para que les sea significativas.

"Son complejas, me parecen mejor las actividades del plan 1993" (D8, F, 2do.)

"No hay cómo aplicarlo, lo que pasa ahí es cuando uno debe hacer las adecuaciones, pero la realidad es otra, las evaluaciones son otras, la vida es otra, entonces ellos no aterrizan en eso, aunque uno los lleve, si es un relato histórico, algo que sea cercano a ellos, una leyenda, bueno una leyenda de Hermosillo, búscale, pero no, traen de otras partes" (D2, F, $\left.4^{\circ}\right)$.

Por lo que puede observarse, las y los docentes se enfrentan, como lo mencionan Cambra y Palou (2007), a una serie de decisiones que impactan su práctica docente en cuanto al uso de libro de texto, las prácticas sociales de lenguaje establecidas en los planes de estudio, más explícitas en el plan de 2017 que en el del 2011, para el fomento lector y el goce literario. Es claro el conflicto entre lo impuesto en los modelos curriculares con las creencias, 
las representaciones del profesorado con respecto al uso de los libros de texto y sus saberes pedagógico/didácticos en relación con la enseñanza de la lengua y la literatura (Cuesta, 2019).

\subsection{Tradiciones}

En el contexto de la cultura mexicana existen tradiciones como lo son los festejos del "Día de las niñas y los niños", "Día de las madres" o "Día de muertos", eventos que conservan y reproducen significados que pudieran verse reflejados en actividades de lectoescritura y de apreciación literaria en la formación básica. Por esta razón, se les preguntó tanto al alumnado como al profesorado qué tipos de actividades relacionadas con estas tradiciones eran realizadas en el área de Lenguaje y comunicación y cómo eran utilizados sus libros de Español Lecturas y Español y Lengua Materna. Español. La Tabla 6, da cuenta de las respuestas del profesorado que, a su vez, fueron contrastadas con las del alumnado.

Tabla 6

Porcentaje de las actividades de lectoescritura y literatura realizadas durante la celebración de eventos tradicionales. Respuestas del profesorado y estudiantado de una escuela primaria, Hermosillo, Sonora. México. 2020

\begin{tabular}{|c|c|c|c|}
\hline Población & Evento & Actividades relacionadas con la lectura y escritura & Porcentaje \\
\hline \multirow{15}{*}{ |Alumnado } & $\begin{array}{l}\text { Lunes } \\
\text { cívicos }\end{array}$ & Leen poemas, cuentos $u$ otras lecturas incluidas en los libros de texto & 38.2 \\
\hline & \multirow{5}{*}{$\begin{array}{l}\text { Día de las } \\
\text { madres }\end{array}$} & Hacen manualidades como regalo & 74.3 \\
\hline & & La escuela organiza un festejo sólo para ellas & 68.1 \\
\hline & & $\begin{array}{l}\text { El/la docente les pide escriban un poema, o cuento, o relato, como regalo para } \\
\text { el Día de las madres }\end{array}$ & 43.7 \\
\hline & & Ustedes realizan bailables en el festejo del Día de las madres & 18.0 \\
\hline & & $\mathrm{El} / \mathrm{la}$ docente les pide leas y ensayes una obra de teatro como parte del festejo & 10.5 \\
\hline & \multirow{8}{*}{$\begin{array}{c}\text { Día de las } \\
\text { niñas y los } \\
\text { niños }\end{array}$} & Lo festejan con dulces, pastel, comida, piñata, etc. & 70.8 \\
\hline & & Realizan presentaciones de teatro & 15.3 \\
\hline & & Lo festejan con actividades de lectura o escritura & 14.6 \\
\hline & & $\begin{array}{l}\text { Realizan juegos basados en los libros de texto de Español Lengua Materna y } \\
\text { Español lecturas }\end{array}$ & 13.9 \\
\hline & & La escuela les presenta música en vivo & 12.5 \\
\hline & & Leen poemas, o cuentos, u otros géneros & 11.8 \\
\hline & & Realizan presentaciones de danza & 8.4 \\
\hline & & Cantan, o tocan algún instrumento & 8.4 \\
\hline & $\begin{array}{l}\text { Día de } \\
\text { muertos }\end{array}$ & Realizan actividades de lectura y escritura el Día de muertos & 41.7 \\
\hline \multirow{5}{*}{ Profesorado } & \multirow{5}{*}{ Tradiciones } & $\begin{array}{l}\text { Como actividad del Día de muertos, instruye al estudiantado para que } \\
\text { elaboren manualidades }\end{array}$ & 83.4 \\
\hline & & $\begin{array}{l}\text { El Día de muertos, organiza actividades que involucren el uso de la lengua } \\
\text { oral y escrita }\end{array}$ & 83.3 \\
\hline & & $\begin{array}{l}\text { Las actividades de lectura y escritura que esta escuela realiza el Día de } \\
\text { muertos favorecen las múltiples formas de expresión }\end{array}$ & 83.3 \\
\hline & & Lee al alumnado obras literarias los lunes cívicos & 41.6 \\
\hline & & $\begin{array}{l}\text { Durante los festejos como el Día de las madres y Día de las niñas y los niños, } \\
\text { fomenta la apreciación de obras literarias }\end{array}$ & 25 \\
\hline
\end{tabular}

Fuente: Elaboración propia a partir del procesamiento de datos, 2020 
Las respuestas del profesorado en relación con las tradiciones, particularmente en la del Día de Muertos, muestran el porcentaje más alto, es decir, que el profesorado declara que la mayoría de las veces instruye al estudiantado para que elaboren manualidades durante esta celebración (83.3\%), organiza actividades que involucren el uso de la lengua oral y escrita (83.3\%); y cree que las actividades de lectura y escritura favorecen las múltiples formas de expresión (83.3\%).

Las respuestas de las y los estudiantes no coinciden con las declaraciones hechas por el profesorado, pues, como se muestra en la Tabla 5, y de acuerdo con la frecuencia con la que se festeja el "Día de las niñas y los niños", el porcentaje más alto (70.8\%) tiene que ver celebrar con dulces, pastel, comida y piñata; mientras que el "Día de las madres", más bien es la escuela la que realiza el festejo solo para ellas (68.1\%). El resto de las actividades como cantar o tocar un instrumento, escuchar música en vivo, realizar presentaciones de danza y teatro, leer poemas, o cuentos, u otros géneros, realizar actividades de lectura o escritura o juegos basados en los libros de texto de Español, Lengua Materna. Español y Español Lecturas, nunca se realizan o la mayoría de las veces, no. Tanto docentes como estudiantes coinciden en que durante la celebración del “Día de muertos” algunas veces sí y algunas veces no, realizan actividades de lectura y escritura. Lo mismo sucede con el hecho de leer poemas, cuentos u otras lecturas incluidas en los libros de texto durante la celebración de los lunes cívicos.

En la entrevista focal, el profesorado refirió que la literatura se vincula con los festejos del "Día de las madres", "Día de las niñas y los niños" o "Día de muertos" porque son los padres y madres de familia quienes deciden qué actividades se llevan a cabo.

"Aquí un Día de madres no hacemos actividad de los niños para las mamás. En lo que yo tengo aquí en la escuela, nunca se ha hecho, porque se hace especialmente para las mamás y nada más para las mamás. Día de las niñas y los niños, puro juego" (D2, F, $4^{\circ}$ ).

"No, es que aquí se hace lo que los papás quieren... se hizo una encuesta y los papás dijeron que no querían festival, quieren festejo en la noche, papá con mamá, que no quieren festivales donde los niños vayan" (D9, F, $6^{\circ}$ )

"Donde se ve más plasmado es en la feria del libro. Ya cada uno, cada maestro, en las fechas del Día de muertos, Día de las madres, pues sí, habrá maestros que a lo mejor sí hagan poemas, una carta, pero más explícito se ve más plasmado el uso de recursos literarios en la feria del libro" (D11, M, $6^{\circ}$ ). 
A partir de lo observado en los lunes cívicos, se encontró que el profesorado promueve entre sus estudiantes la importancia del hábito de la lectura, sin embargo, ellos no recomiendan lecturas de obras literarias. En la mayoría de los casos las y los estudiantes leyeron fragmentos de lecturas escogidas por ellos mismos. Otro aspecto observado fue la preparación del festejo para el 14 de febrero, Día de San Valentín, donde docentes de cada grupo elaboraron periódicos murales alusivos a ese festejo. En tales periódicos murales, no se observó ningún fragmento de las obras literarias. Probablemente, y coincidiendo con Munita (2013), la falta de promoción de textos literarios y otros vacíos, puedan deberse los saberes de estos docentes en torno su conocimiento literario, las perspectivas que tienen sobre la lectura y sobre ellos mismos como lectores y su misma experiencia lectora.

\subsection{La escuela primaria y el desarrollo humano}

Como elemento no visible de la literacidad se encuentran los participantes ocultos y las creencias del profesorado sobre el Plan curricular para la educación básica. En este sentido, la Tabla 7, refleja los resultados del cuestionario sobre las creencias del profesorado en torno al debate sobre si la educación primaria es la base para iniciar el proceso de crear individuos productivos y aptos para las competencias de la sociedad, o, es la base para seguir un proceso enfocado al desarrollo humano (SEP, 2017). Cabe destacar que solo el $8.3 \%$ del personal docente está totalmente de acuerdo en que la promoción del arte en la vida del estudiantado podría hacerlos incompetentes ante las exigencias del mercado laboral. Por el contrario, el $91.7 \%$ del profesorado cree que se debe preparar al estudiantado para sensibilizarlo por medio de las artes con el fin de que contribuya a trasformar la sociedad. Asimismo, profesoras y profesores muestran estar mayormente de acuerdo (91.6\%) en tres ideas: en que el estudiantado debe prepararse para integrarse al campo laboral y ser buenos ciudadanos, en crear una cultura escolar basada en la promoción y difusión de la literatura y otras artes; y en que el planteamiento curricular instruya a todas las escuelas a fomentar la igualdad de oportunidades. Además, el $83.3 \%$ del profesorado cree que es importante capacitar al estudiantado para que se adapten a la sociedad y al mercado de trabajo. 
Tabla 7

Porcentaje de las preferencias del profesorado de una escuela primaria en relación con sus creencias sobre el enfoque humanista del Plan Curricular de educación (art. 7 y 8 . LGE, SEP, 20017a). Hermosillo, Sonora, México. 2020

\begin{tabular}{l|l}
\hline \hline El profesorado cree que: & Porcentaje \\
\hline \hline $\begin{array}{l}\text { Se debe preparar al estudiantado para sensibilizarlo por medio de las artes para que contribuya a } \\
\text { trasformar la sociedad }\end{array}$ & 91.7 \\
\hline $\begin{array}{l}\text { Es importante crear una cultura escolar basada en la promoción y difusión de la literatura y otras } \\
\text { artes }\end{array}$ & 91.6 \\
\hline $\begin{array}{l}\text { Es importante que el planteamiento curricular instruya a todas las escuelas a fomentar la igualdad } \\
\text { de oportunidades }\end{array}$ & 91.6 \\
\hline El estudiantado debe prepararse para integrarse al campo laboral y ser buenos ciudadanos & 91.6 \\
\hline Es importante capacitar al estudiantado para que se adapten a la sociedad y al mercado de trabajo. & 83.3 \\
\hline $\begin{array}{l}\text { La promoción del arte en la vida del estudiantado podría hacerlos incompetentes ante las } \\
\text { exigencias del mercado laboral }\end{array}$ & 8.3 \\
\hline \hline
\end{tabular}

Fuente: Elaboración propia a partir del procesamiento de datos, 2020

Estas concepciones sobre el Plan curricular de educación básica fueron reflexionadas en el grupo focal por profesoras y profesores quienes expresaron la incongruencia de este, pues ven que por un lado se pide la formación humanista-socioemocional, y por otro, tiene la exigencia de dar resultados de calidad en habilidades lectoras y matemáticas, presión ejercida por los organismos internacionales.

"Yo concibo que el programa busca eso, unir ambas cosas...sin embargo es difícil toda la pretensión que quiere el programa...Yo pienso que el diseño, probablemente esté mal, si se pretende eso, hay un mal diseño entonces del plan" (D11, M, $6^{\circ}$ ).

"Yo creo que la limitante más fuerte es la estructura misma del programa porque es incongruente querer priorizar por ejemplo el área humana en el área socioemocional y de las artes, si llegan evaluaciones nacionales e internacionales enfocadas sólo en español y matemáticas, que si bien no se puede evaluar la parte socioemocional, si se le puede pasar importancia a lo mejor a aquellos otros dos componentes en donde inconscientemente hacen que el maestro se oriente a priorizar y a enfocarse a las otras dos áreas, porque saben que son donde se va a estar observando y midiendo la calidad de la educación de la escuela" (D8, F, $2^{\circ}$ ).

La incongruencia a la que se refieren las y los docentes está en concordancia con lo que menciona Gee (2004, p. 24), pues las prácticas escolares dentro y fuera del aula obedecen más a las exigencias políticas y a las perspectivas de las instituciones hegemónicas, provocando con ello que el profesorado difiera de sus propios valores e identidades que se le exigen fuera del dominio escolar. 


\subsection{Actividades didácticas para la lectura y literatura}

Para comprender las acciones que ejecutan los participantes en el evento de literacidad en torno a la formación literaria y con apoyo de los libros de texto, se les preguntó a las y los estudiantes de educación primaria la frecuencia con la que el profesorado pone en práctica actividades didácticas relacionadas con la lectura y la literatura. Los resultados sobre las actividades didácticas que las y los niños refieren de sus profesoras y profesores se muestran en la Tabla 8.

Tabla 8.

Porcentaje de frecuencia de realización de actividades de lectura y el uso de los libros de texto desde la visión de niñas y niños de una escuela primaria, Hermosillo, Sonora, México. 2020

\begin{tabular}{l|c}
\hline \hline El profesorado: & Porcentaje \\
\hline \hline Solicita a las y los estudiantes que lean en voz alta, uno a la vez, las lecturas de los libros de & \\
Español Lengua Materna o Español Lectura & 59.1 \\
\hline $\begin{array}{l}\text { Lee al estudiantado las lecturas contenidas en los libros de texto de Español Lengua Materna o } \\
\text { Español Lectura }\end{array}$ & 40.3 \\
\hline $\begin{array}{l}\text { Realiza juegos en clase basados en los libros de texto de Español Lengua Materna, Español } \\
\text { Lectura }\end{array}$ & 39.6 \\
\hline $\begin{array}{l}\text { Solicita a las y los estudiantes que lean en silencio las obras literarias contenidas en los libros de } \\
\text { Español Lengua Materna o Español Lectura }\end{array}$ & 38.9 \\
\hline $\begin{array}{l}\text { Solicita a las y los estudiantes que lean en voz alta, todos juntos, las lecturas de los libros de } \\
\text { Español Lengua Materna o Español Lectura }\end{array}$ & 28.5 \\
\hline $\begin{array}{l}\text { Comenta las lecturas (cuentos, novelas, poesía, etc.) contenidas en los libros de texto de Español } \\
\text { Lengua Materna o Español Lectura }\end{array}$ & 25.7 \\
\hline Usa películas o documentales basados en obras literarias (cuentos, novelas, poesía, etc.) & 25.7 \\
\hline \hline
\end{tabular}

Fuente: Elaboración propia a partir del procesamiento de datos, 2020

De acuerdo con las respuestas de las y los niños en relación con las actividades que el profesorado realiza en torno a las lecturas de los libros de Español Lengua Materna o Español Lecturas, el porcentaje más alto (59.1\%) lo tiene el hecho de solicitar a cada uno que lean en voz alta, uno a la vez; mientras que, el resto de las actividades didácticas se encuentran por debajo del $50 \%$ en las respuestas de la mayoría de las veces sí y siempre. Es decir, que más del $50 \%$ de las frecuencias: algunas veces sí y otras veces no, la mayoría de las veces no y nunca son realizadas por el profesorado las actividades didácticas como: leer todos juntos en voz alta a la vez, ver películas o documentales basados en obras literarias, comentar con el alumnado las lecturas de los libros texto, leer a los y las niñas el contenido, realizar juegos basados en los libros de texto o bien solicitar al alumnado que lean en silencio las obras literarias.

La observación permitió contrastar los datos anteriores. Específicamente, se advirtió que el profesorado en los primeros años (primero y segundo, los que pertenecen al plan 2017) 
realiza actividades como: leer para las y los estudiantes en voz alta de forma pausada, deteniéndose en cada texto haciendo participar a los niños en cada comentario. Además, hacen que las niñas y los niños lean en voz alta uno por uno y también les piden que lean en silencio un texto para luego comentarlo. Con estas actividades el profesorado desarrolla habilidades comunicativas, léxicas y fonológicas y niveles de comprensión lectora a nivel literal y probablemente inferencial (Lastre et al., 2018; Riffo et al., 2018).

En el caso de un grupo de cuarto grado, tras leer un poema en voz alta, durante el juego de "la papa caliente", la maestra realizó preguntas como: ¿qué es un poema?, ¿qué es un verso?, ¿qué nos provocan los poemas? En el caso de grupos de sexto grado, un docente entregó a los estudiantes un cuento con preguntas integradas tales como: ¿qué sucede al principio del cuento?, ¿cuál es el conflicto?, ¿cuál es el desenlace?, ¿cuál es el escenario donde acontecen los hechos?, ¿cuándo ocurren los hechos que se narran?, ¿en qué persona gramatical está escrito?, ¿en qué discurso se cuenta la historia del cuento?, ¿qué es un cuento?

Desde la teoría de la recepción, se pone énfasis en las reacciones que la lectura provoca en los lectores: sentimientos de alegría, tristeza, nostalgia o alguna emoción que haga eco con su historia personal, es decir, alguna circunstancia que parezca coincidir con un evento personal. Por lo tanto, las preguntas realizadas por el profesorado se acercan más a enfatizar el metalenguaje de la lectura, por ejemplo, cuando se pregunta ¿qué es un cuento? ¿qué es un verso? ¿qué es un poema?, pero no buscan alertar al lector/a sobre el mundo representado, los valores, virtudes de la sociedad en consonancia con la interpretación que el niño o la niña realice o con su contexto particular, como lo refieren Bataller-Català y Reyes-Torres (2019); Condemarín (2003); Gee (2004); Kucer (2014); Mendoza-Fillola (2003); Sánchez-Corral (2003) y Street (2017).

\subsection{Literatura: arte y/o comprensión lectora}

Las creencias sobre si la literatura debe tratarse como arte y como instrumento para mejorar la comprensión lectora o solo como herramienta para alfabetizar, las y los docentes tienen opiniones encontradas. Por un lado, el profesorado menciona que las exigencias sobre la lectura hacen que se olvide que la literatura es arte, pero por otro, menciona que van de la mano:

"Sería bueno que fuera como la primera parte, pero realmente es complicado porque el programa nos marca actividades muy prácticas, no hay el tiempo, sí sería excelente, que 
realmente la literatura fuera como un eje para hacer las actividades que nos piden, pero pues si es complicado en mi caso, no sé los otros maestros" (D7, F, 4to).

"Van de la mano las dos, no podemos decir que no sirvan, tienen que llevarse a la par las dos" (D1, F, 2do).

"Son complemento". (D11, M, 6to)

“No puedes decir que sólo para alfabetizar, no, tiene que ir de la mano” (D8, F, 2do).

Las afirmaciones y creencias del profesorado, obtenidas en el grupo focal, se constatan con las respuestas del cuestionario que ellos mismos realizaron, como podemos observar en la Tabla 9.

Tabla 9.

Porcentaje del profesorado de una escuela primaria sobre sus concepciones en torno a la formación literaria, Hermosillo, Sonora, México. 2020

\begin{tabular}{l|c}
\hline \hline El profesorado cree: & Porcentaje \\
\hline \hline $\begin{array}{l}\text { La lectura de obras literarias puede fomentar en el alumnado un gusto por las diferentes } \\
\text { manifestaciones artísticas }\end{array}$ & 91.7 \\
\hline La formación literaria promueve la igualdad a través de las obras literarias & 91.7 \\
\hline Es importante fomentar el gusto por las obras literarias & 91.6 \\
\hline $\begin{array}{l}\text { Los textos literarios son un medio de aprendizaje para el niño porque favorece su desarrollo y se } \\
\text { ve reflejado en otras materias }\end{array}$ & 91.6 \\
\hline La formación académica normalista, relacionada con la enseñanza de la literatura es la adecuada & 83.4 \\
\hline \hline
\end{tabular}

Fuente: Elaboración propia a partir del procesamiento de datos, 2020

El $91.7 \%$ del profesorado cree, en la mayoría de las veces y siempre, que es importante fomentar el gusto por las obras literarias, que los textos literarios son un medio de aprendizaje para el niño porque favorece su desarrollo y se ve reflejado en otras materias, que la lectura de obras literarias puede fomentar en el alumnado un gusto por las diferentes manifestaciones artísticas, y que a través de la enseñanza de las obras literarias se promueve la igualdad. Sólo el $83.3 \%$ de las y los docentes concibe que la formación académica normalista, relacionada con la enseñanza de la literatura es la adecuada.

Sin embargo, las declaraciones tanto en el grupo focal como en el cuestionario distan con la práctica en el aula. Durante la observación se advirtió que la escuela primaria lleva un "plan de lectura escolar". Todos los grupos cuentan con un formato en hoja tamaño carta que lleva por título "registro de lectura diaria", el cual lleva inscrito el nombre del mes, el número de Días correspondientes al mes, nombre del estudiante, grado y sección, libro o título, tiempo de lectura y firma. A partir de este "plan de lectura", se infiere que la lectura se promueve de forma normativa, donde el profesorado actúa más como evaluador que como promotor de la 
literatura. Aunque este "plan de lectura" forma parte del Plan Nacional de Lectura y sigue la Estrategia 11+5, esta acción es contradictoria con el ideal de que el profesorado debe compartir y transmitir al estudiantado el goce estético que provoca la lectura de obras literarias. Esta idea se expone en el mismo plan de estudios, donde el profesorado habrá de dominar un conjunto de prácticas de lectura y escritura para mantener una relación con los estudiantes de lector a lector (SEP, 2017, p. 179).

La formación literaria implica maneras de fomentar la literatura desde la misma enseñanza de la lengua (Colomer, 2001, p.17). Se asume que la clase de español es el escenario donde directamente se proyecta el fomento del gusto por la lectura y de la literatura en particular, sin embargo, durante el trabajo de campo no se observó un seguimiento en la labor del docente en cuanto a la promoción del gusto por las obras literarias más representativas, aún y cuando cuentan con un "plan de lectura escolar" y con bibliotecas de aula equipadas con material pertinente.

Los objetivos que persigue la educación literaria en cuanto a favorecer la comprensión y hábito de lectura, o la capacidad para interpretar textos, disfrutarlos y producirlos no fueron detectados en el contexto de la escuela primaria estudiada (Sánchez-Corral, en MendozaFillola, 2003, p. 321). Estos datos coinciden con el aporte de Aco (2016), quien plantea la necesidad de incentivar en los docentes de primaria un gusto por las obras literarias para que la literatura sea fomentada en el contexto escolar. Este estudio es de suma importancia para este trabajo, pues generalmente se diseñan estrategias de fomento a la lectura para estudiantes, mas no para profesores. Coincidimos con este aporte, pues, quizás de esta forma puedan verse proyectadas las prácticas sociales del lenguaje vinculadas con la literatura en las diferentes actividades del contexto escolar, y con ello avanzar hacia la formación de lectores críticos a través de la literatura, según se expone en el plan de estudios (SEP, 2017, p.181).

\section{Conclusiones}

Describir cómo son los eventos y prácticas de literacidad en torno al fomento y enseñanza de la apreciación literaria en una escuela primaria pública de Hermosillo, Sonora, México, permitió comprender que la literacidad literaria tiene un carácter rizomático. Esta caracterización, derivada de las inferencias a las que se han llegado en este trabajo, son resultado de la observación participante, de las percepciones tanto del alumnado como del profesorado del centro educativo en cuestión, por lo que no es posible hacer generalizaciones. 
Sin embargo, sí permite adentrarse en la comprensión de todas las partes involucradas, por ejemplo, el cómo las creencias, los saberes y las representaciones del profesorado inciden en la puesta en práctica de las visiones curriculares o de las políticas educativas para el fomento de la lectura. El carácter rizomático de la literacidad literaria entiende que todos los componentes, tantos de los eventos como los de las prácticas se afectan entre sí, al mismo tiempo, en una red interconectada. La cultura escolar es tan importante como la oficialización de las pautas sociales de lectura, las creencias del estudiantado, los saberes del profesorado, el desarrollo tecnológico y la resignificación de la lectura, entre otros.

Los eventos y prácticas de literacidad en torno al fomento y la apreciación literaria en la escuela primaria pública estudiada tienen como partícipes principales a sus docentes y estudiantes. No obstante, también están aquellos participantes que no son directamente observables, como lo son las creencias, percepciones y saberes del profesorado, las instituciones como la Secretaría de Educación Pública (SEP) y la dirección escolar, el Plan de estudios para educación básica, el programa nacional de lectura y escritura, los padres de familia y los Libros de Texto a manera de manuales de enseñanza. El evento de literacidad se da en el contexto de la escuela de educación básica, donde observamos una biblioteca escolar en desuso, sustituida por las bibliotecas de aula. La preferencia por estas últimas obedece a la Política Nacional de Lectura, específicamente a la Estrategia 11+5, vigente al Día hoy.

En adición a lo anterior, los manuales de enseñanza, los libros de texto Español Lecturas, a partir de tercer grado, no son usados (nos referimos a los grados que llevan el plan 2011). La respuesta a esta circunstancia y de acuerdo con las y los docentes es que estos libros de texto no están vinculados con el libro de texto base Español, es decir, que este libro de texto no tiene indicaciones explícitas que hagan referencia en sus actividades a los otros manuales. No fue el objetivo de este trabajo, pero podría convertirse en una futura investigación el analizar la vinculación y complementación interdisciplinaria que se espera de los contenidos de los libros de texto. De haber un vacío, el Estado podría atender las nuevas ediciones de tal forma que el profesorado sienta la utilidad de un artefacto rico en variedad de géneros literarios, en el que se invierte dinero que, desafortunadamente, no es aprovechado.

Por otra parte, es posible que se esté presentando una tensión entre los saberes pedagógico/didácticos con los saberes de las y los docentes en relación con el uso de los libros de texto como orientadores de las metodologías de enseñanza. El profesorado considera, por ejemplo, que las prácticas sociales del lenguaje contenidas en los libros de texto del plan 2017 son complejas y no están acordes a los intereses de las y los niños de la escuela 
primaria. Por su experiencia, el profesorado, considera que el Plan de Estudios de 1993 era más asertivo en planificación de las actividades y en la consideración de la realidad social del estudiantado.

Por lo que se refiere a las celebraciones culturales como ceremonias propicias para llevar a cabo actividades didácticas dentro de los eventos de literacidad, vemos una desvinculación con las dinámicas de lectoescritura y con la promoción de la literatura y la apreciación literaria. Esto tiene una excepción, la celebración del "Día de muertos", ya que esta tradición ha buscado ser reafirmada por las autoridades educativas y por la naturaleza de esta, es decir, que parte de la celebración consiste en leer y escribir calaveritas o poemas que con humor, ironía, sátira y sarcasmo critican las creencias, costumbres y valores de la sociedad.

Dentro de las prácticas de literacidad, las y los docentes entrevistados creen que existe una incongruencia en los planes curriculares de 2011 y 2017 para la educación básica. La incongruencia consiste en que, por un lado y específicamente, el Plan curricular de 2017 enfatiza el desarrollo humano a través de las artes y actividades socioemocionales, pero por el otro, prioriza la calidad educativa a través de pruebas de organismos nacionales e internacionales enfocados en matemáticas y español.

Como limitación de la investigación se puede mencionar que el presente es un caso particular, por lo que las conclusiones se limitan al ámbito escolar estudiado. Otra limitante fue la suspicacia del profesorado, manifestada en el temor a que sus declaraciones tuvieran represalias de parte de las autoridades administrativas. Sin embargo, es posible ampliar la investigación a aspectos más puntuales, por ejemplo, la relación de las prácticas sociales del lenguaje establecidas en el plan de estudios de 2017 con la comprensión, reflexión y experiencia del profesorado de estas con sus propios saberes, trayectorias docentes y su perfil lector.

En conclusión, existen eventos y prácticas de literacidad que impiden que el fomento y enseñanza de la literatura y la lectoescritura promuevan la construcción de significados, donde el estudiantado erija su propio discurso y donde se haga posible la interdisciplinariedad e intertextualidad. Eventos y prácticas que, aunque entrelazados, pueden atenderse de forma particular para mejorar la literacidad literaria. 


\section{Referencias}

Aceves-Azuara, Itzel., y Mejía-Arauz, Rebeca. (2015). El desarrollo de la literacidad en los niños. En Rebeca Mejía-Arauz (Coord.), Desarrollo psicocultural de niños mexicanos. Guadalajara, Jalisco:

ITESO. https://www.researchgate.net/publication/283874682 Desarrollo Psicocultural de Nin os Mexicanos

Aco, Leandro. (2016). Incentivar el gusto por la literatura en niños de educación primaria: circulo de lectura para docentes (Tesis de maestría publicada en línea). Universidad Iberoamericana Puebla, Puebla, México. https://repositorio.iberopuebla.mx/bitstream/handle/20.500.11777/2001/Aco\%20Aco\%2 $\underline{\text { oLeandro.pdf? sequence }=5 \text { \&isAllowed }=y}$

Baena-Paz, Guillermina. (2017). Metodología de la investigación. México: Grupo Editorial Patria.

http://www.biblioteca.cii.gob.mx/Archivos/Materiales de consulta/Drogas de Abuso/Ar ticulos/metodologia\%20de\%20la\%20investigacion.pdf

Barton, David., y Hamilton, Mary. (2004). La literacidad entendida como práctica social. En Virginia Zavala, Mercedes Niño-Murcia y Patricia Ames (Ed), Escritura y sociedad. Nuevas perspectivas teóricas y etnográficas (pp. 109-139). Lima: Red para el Desarrollo de las Ciencias Sociales en el Perú. https://www.estudiosdelaescritura.org/uploads/4/7/8/1/47810247/zavala et al 2004 es critura y sociedad.nuevas perspectivas.pdf

Bataller Català, Alexandre., y Reyes Torres, Agustín. (2019). La pedagogía de las multiliteracidades y la experiencia estética como elementos claves en la enseñanza y el aprendizaje de lenguas. Por la consolidación de un nuevo paradigma. Revista Nebrija de Lingüística Aplicada a la Enseñanza le Lenguas, 13(26), 13-30. https://doi.org/10.26378/rnlael1326306

Cambra, Margarida., y Palou, Juli. (2007). Creencias, representaciones y saberes de los profesores de lenguas en las nuevas situaciones plurilingües escolares de Cataluña. Cultura y Educación, 19(2), 149-163. https://doi.org/10.1174/113564007780961651

Cassany, Daniel. (2008). Prácticas letradas contemporáneas. México: Ríos de Tinta.

Colomer, Teresa. (1998). La formació del lector literari. Barcelona: Barcanova.

Colomer, Teresa. (2001). La enseñanza de la literatura como construcción del sentido. Lectura y vida, 22(4), 1-19.

Condemarín, Mabel. (2003). Consideraciones sobre la enseñanza de y en lengua materna. En Ingrid Jung y Luis Enrique López (Eds.), Abriendo la escuela: lingüística aplicada a la enseñanza de lenguas (pp. 182-212). Madrid: Morata.

Cuesta, Carolina. (2019). Didáctica de la lengua y la literatura, políticas educativas y trabajo docente. Problemas metodológicos de la enseñanza (Colección Archivos de Didáctica. Serie fichas de Investigación). Argentina: Mino y Dávila Editores. 
Denzin, Norman K. (1978). The research act: a theoretical introduction to sociological methods. New York: Mc Graw Hill Glaser.

Diario Oficial de la Federación. (15 de mayo de 2019). DECRETO por el que se reforman, adicionan y derogan diversas disposiciones de los artículos 3o., 31 y 73 de la Constitución Política de los Estados Unidos Mexicanos, en materia educativa. https://www.dof.gob.mx/nota detalle.php?codigo=5560457\&fecha=15/05/2019\&print=tr $\underline{\text { ue }}$

Díaz-Plaja, Ana. (2002). El lector de secundaria. En Belén Muñoz (Ed.), Aspectos didácticos de la lengua y la literatura, 12 (pp. 171-197). Zaragoza: Universidad de Zaragoza. Instituto de Ciencias de la Educación.

Elías, María Esther. (2015). La cultura escolar: Aproximación a un concepto complejo. Revista Electrónica Educare, 19(2), 285-301. http://dx.doi.org/10.15359/ree.19-2.16

Escolano Benito, Agustín. (2020). La escuela, una organización ritualizada. Revista Mexicana de Historia de la Educación, 8(16), 80-105. https://doi.org/10.29351/rmhe.v8i16.277

Fardella, Carla., y Carvajal Muñoz, Francisca. (2018). Los estudios sociales de la práctica y la práctica como unidad de estudio. Psicoperspectivas, 17(1), 1-12. https://doi.org/10.5027/psicoperspectivas-vol17-issue1-fulltext-1241

Galindo Aguilar, Nélida. (2009). Ceremonias como parte de la cultura escolar (Tesis de Licenciatura en Psicología educativa). Universidad Pedagógica Nacional de México, México D.F., México. http://200.23.113.51/pdf/26527.pdf

Gee, James Paul. (2004). Oralidad y literacidad: de El Pensamiento salvaje a Ways with Words. En Virginia Zavala, Mercedes Niño-Murcia y Patricia Ames (Ed), Escritura y sociedad. Nuevas perspectivas teóricas y etnográficas (pp. 23-46). Lima: Red para el Desarrollo de las Ciencias Sociales en el Perú. https://www.estudiosdelaescritura.org/uploads/4/7/8/1/47810247/zavala et al 2004 es critura y sociedad.nuevas perspectivas.pdf

Gee, James Paul. (2015). Literacy and education. New York. Routledge.

Geertz, Clifford. (2003). La interpretación de las culturas (12ª ed.). Barcelona: Gedisa.

Goetz, Judith., y LeCompte, Margaret. (1988). Etnografía y diseño cualitativo en investigación educativa. España: Morata.

Gutiérrez-Álvarez, Edith., y Rafael-Ballesteros, Zoila. (2020). Rituales del estudiante normalista en su marco de práctica docente en la escuela secundaria. Praxis $\begin{array}{lll}\text { Investigativa. } & \text { REDIE, }\end{array}$ https://redie.mx/librosyrevistas/revistas/praxisinv23.pdf

Hamilton, Mary. (2000). Expanding the new literacy studies: using photographs to explore literacy as social practice. En David Barton, Mary Hamilton y Roz Ivanic (Eds.), Situated literacies. Reading and writing in context (pp. 16-34). Nueva York: Routledge. 
Hamui-Sutton, Alicia., y Varela-Ruiz, Margarita. (2013). La técnica de grupos focales. Investigación en Educación Médica, 2(5), 55-60. https://www.redalyc.org/pdf/3497/349733230009.pdf

Hernández, Roberto., Fernández, Carlos., y Baptista, Pilar. (2014). Metodología de la investigación (6ta. ed.). Ciudad de México: Mc Graw Hill. https://www.uca.ac.cr/wpcontent/uploads/2017/10/Investigacion.pdf

Julio-Maturana, Cristina., Conejeros-Solar, Leonor., Rojas-Aravena, Carola., MohammadJiménez, Marcela., Castillo, Rubí., y Cortés-León, Yasna. (2016). Desencuentro cultural en el aula. Una barrera al aprendizaje de niños y niñas en situación de pobreza. Revista Mexicana de Investigación Educativa RMIE, 21(68), 71-94. http://www.scielo.org.mx/pdf/rmie/v21n68/1405-6666-rmie-21-68-00071.pdf

Kahn, Joel. (1975). El concepto de cultura: textos fundamentales. Barcelona: Anagrama.

Kucer, Stephen. (2014). Dimensions of Literacy: A Conceptual Base for Teaching Reading and Writing in School Settings. New York. Routledge.

Lamas, Florencia. (2017). Poesía en la escuela: los maestros, sus lecturas y sus creencias. Bellaterra Journal of Teching \& Learning Language \& Literature, 10(4), 32-48. https://doi.org/10.5565/rev/jtl3.699

Lara-Guijarro, Enriqueta., y Ballesteros-Velázquez, Belén. (2008). Métodos de investigación en educación social (2da. Reimp.). Madrid: Universidad nacional de Educación a Distancia.

Lastre, Karina Sofía., Chimá López, Fradit De Jesús., y Padilla Pérez, Anuar Rafael. (2018). Efectos de la lectura en voz alta en la compresión lectora de estudiantes de primaria. Encuentros, 16(1), 11-22 doi: https://doi.org/10.15665/.v16i01.945

Martínez, Miguel. (1999). La investigación cualitativa etnográfica en educación. México: Trillas.

Mendoza-Fillola, Antonio. (1998). Tú, lector: aspectos de interacción texto-lector en el proceso de lectura. Barcelona: Octaedro.

Mendoza-Fillola, Antonio. (2004). La educación literaria, bases para la comprensión lectoliteraria. Málaga: Ediciones Aljibe.

Mendoza-Fillola, Antonio (Coord.). (2003). Didáctica de la Lengua y la Literatura para Primaria. Madrid: Pearson Educación.

Mendoza-Fillola,Antonio. (2001). El intertextolector: el espacio de encuentro de las aportaciones del texto con las del lector. Cuenca: Ediciones de la Universidad de CastillaLa Mancha.

Montes-Silva, Melanie Elizabeth y López-Bonilla, Guadalupe. (2017). Literacidad y alfabetización disciplinar, enfoques teóricos y propuestas pedagógicas. Perfiles educativos, $39(155)$,

162-178. https://doi.org/10.22201/iisue.24486167e.2017.155.58062 
Munita, Felipe. (2013). Creencias y saberes de futuros maestros (lectores y no lectores) en torno a la educación literaria. Ocnos. Revista de Estudios Sobre Lectura, (9), 69-88. https://doi.org/10.18239/ocnos 2013.09.04

Munita, Felipe. (2018). "Para mí todos eran cuentos": incidencia de la formación docente en las creencias y saberes sobre literatura infantil y juvenil. Catalejos. Revista sobre lectura, formación de lectores y literatura para niños, 3(6), 102-125. https://fh.mdp.edu.ar/revistas/index.php/catalejos/article/view/2507/2773

Muñoz, Carla., Lobos, Constanza., y Valenzuela, Jorge. (2020). Disociaciones entre discurso pedagógico y prácticas lectoras en futuros profesores: pistas para la formación docente. Revista Fuentes, 22(2), 203-211. https://doi.org/10.12795/revistafuentes.2020.v22.i2.07

Orozco-López, María Teresa., y Pérez-Amezcua, Luis Alberto. (2021). El triángulo "L" en México: lectura, literatura y literacidad. Sinéctica. Revista electrónica de educación, 56. $1-18$. $\underline{109 \times 2021000100302 \& s c r i p t=s c i}$ arttext http://www.scielo.org.mx/scielo.php?pid=S1665-

Pérez-Gómez, Ángel. (2004). La cultura escolar en la sociedad neoliberal (4 Ed.). Madrid: Morata.

Riffo, Bernardo., Caro, Natalia., y Saéz, Katia. (2018). Conciencia lingüística, lectura en voz alta y comprensión lectora. RLA. Revista de lingüística teórica y aplicada, 56(2), 175-198 doi: http://dx.doi.org/10.4067/S0718-48832018000200175

Sánchez-Corral, Luis. (2003). Didáctica de la literatura: relaciones entre el discurso y el sujeto. En Antonio Mendoza Fillola. (Coord.), Didáctica de la Lengua y la Literatura para Primaria (pp. 291-317). Madrid: Pearson Educación.

Secretaría de Educación Pública. (2011). Plan de estudios 2011. Educación básica. https://www.gob.mx/cms/uploads/attachment/file/20177/Plan de Estudios 2011 f.pdf

Secretaría de Educación Pública. (2017). Aprendizajes Clave para la Educación Integral. Plan y programas de estudio para la educación básica. México: SEP. https://www.planyprogramasdestudio.sep.gob.mx/descargables/APRENDIZAJES CLA VE PARA LA EDUCACION INTEGRAL.pdf

Secretaría de Educación Pública. (2019). Comisión nacional de libros de textos gratuitos. Primaria. https://www.conaliteg.sep.gob.mx/primaria.html

Segura-Munguía, Santiago. (2003). Nuevo diccionario etimológico latín-español y de las voces derivadas. Bilbao, España: Universidad de Deusto.

Street, Brian. (2009). The future of social literacies En Mike Baynham y Mastin Prinsloo (Eds.), The futures of literacy studies (pp. 21-37). Great Britain: Palgrave Macmillan

Street, Brian. (2017). Learning to read from a social practice view: Ethnography, schooling and adult learning. Prospects, 46, 335-344 doi: https://doi.org/10.1007/s11125-017-9411-z 
Trujillo, Francisca. (2010). Educación para la ciudadanía. Los rituales escolares. Trabajo presentado en el Congreso Iberoamericano de Educación, metas 2021. Un congreso para que pensemos entre todos la educación que queremos. Buenos Aires, Argentina, $1-12$.

https://www.adeepra.org.ar/congresos/Congreso\%20IBEROAMERICANO/EDUCCIUD ADANIA/RLE2166 Trujillo.pdf

Vain, Pablo. (2019). Los rituales escolares y las prácticas educativas. EDUNAM: Argentina.

Woods, Peter. (1987). La escuela por dentro. La etnografía en la investigación educativa. España: Paidós.

Zavala, Virginia. (2008). La literacidad o lo que la gente hace con la lectura y la escritura. Textos de didáctica de la lengua y la literatura, 47, 71-79. 


\section{Anexos.}

\section{Anexo 1. Cuestionario para estudiantes}

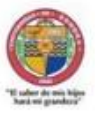

$$
\begin{aligned}
& \text { Universidad de Sonora } \\
& \text { Disión de HumanidadesyBellas Artes } \\
& \text { Departamento de Letrasy Linguifstica } \\
& \text { Maestria en Humanidades }
\end{aligned}
$$

\section{Anexo 2. Cuestionario para docentes}

Universidad de Sonora
División de Humanaidadesy Bellas Artes
Departamento de Letrasy Linguística
Maestria en Humanidades

Cuestionario para el personal docente

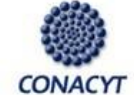

CONACYT

Buenos diastardes:

El propósito de esta investigadón es conocer cómo es la literacidad que se da en un contexto cultural y declaraciones. Este cuestionario es anónimo y sus resultitados se se manejesán para las sigutientes preguntas estricta confidencialidad. Por lo tanto, no tendrán ningún perjuicio para los profesoreses que colaboren en este estudio.

Grado dondeenseña:
Edad:

Sexo:

Instrucciones:

Por favor, indique con una $X$ en la casilla que corresponda que tan de acuerdo o en desacuerdo estácon las siguientes declaraciones, considerando que $1=$ Totalmente en desacuerdo, $2=$ Parcialmente en
desacuerdo, $3=$ Ni en desacuerdo ni de acuerdo $4=$ = Parcialmente de acuerdo, $5=$ Totalmente de acuerdo
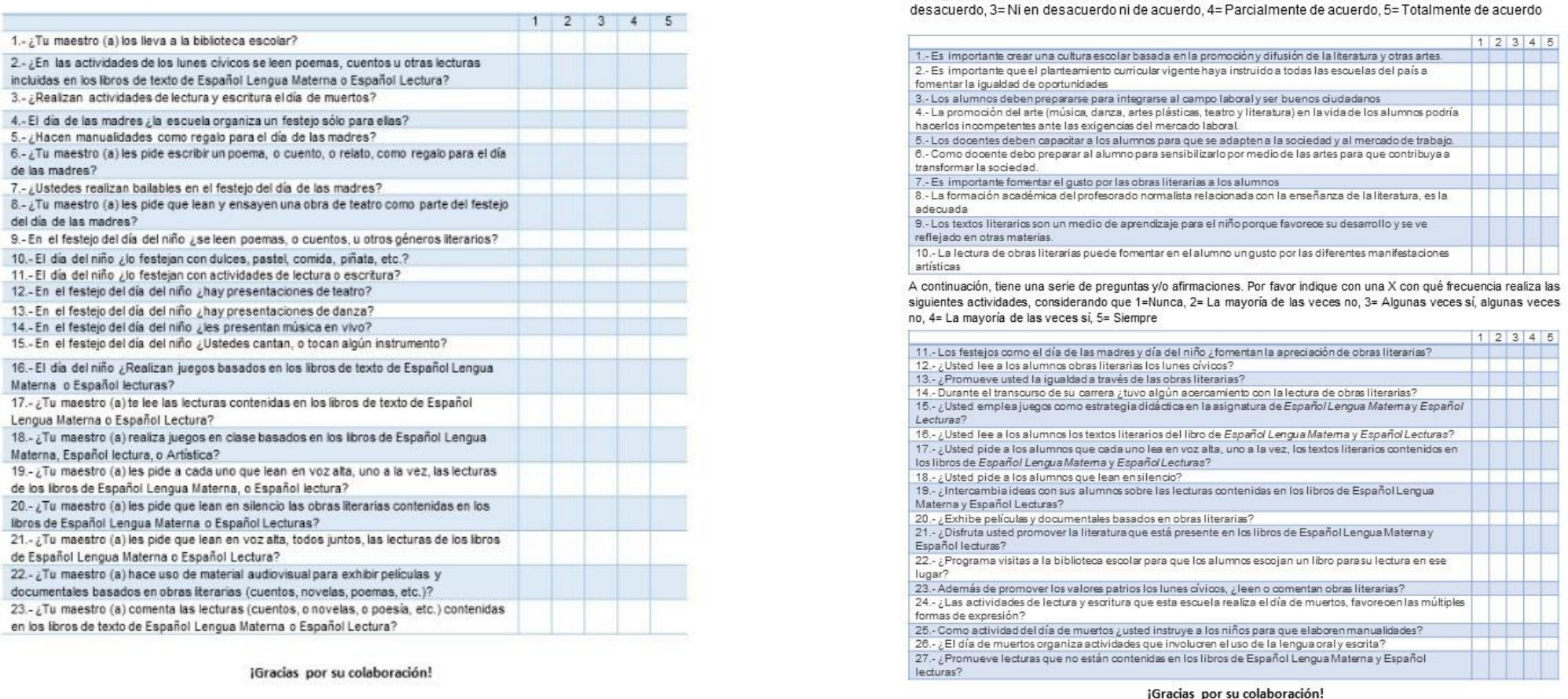

;Gracias por su colaboración 
Revista indizada en

scip/o redalyc.sy latindex DOA J

Distribuida en las bases de datos:

\section{- Dialnet}

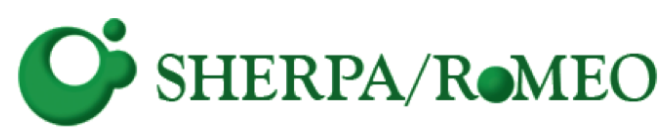

REDIB

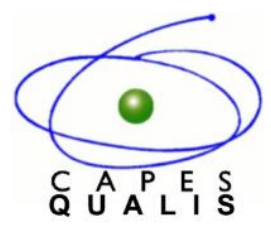

MIAR 